\title{
Design of Iron Coordination Complexes as Highly Active Homogenous Water Oxidation Catalysts by Deuteration of Oxidation Sensitive Sites
}

\author{
Zoel Codolà, ${ }^{[a]}$ Ilaria Gamba, ${ }^{[a]}$ Ferran Acuña-Parés, ${ }^{[b]}$ Carla Casadevall, ${ }^{[b]}$ Martin \\ Clémancey, ${ }^{[d]}$ Jean-Marc Latour, ${ }^{[d]}$ Josep María Lluis, ${ }^{[a]}$ Julio Lloret-Fillol, ${ }^{*,[b],[c]}$ \\ Miquel Costas*,[a]
}

a) Institut de Química Computacional i Catàlisi (IQCC) and Departament de Química, Universitat de Girona. Campus Montilivi; E17071 Girona, Catalonia (Spain) miquel.costas@udg.edu

b) Institute of Chemical Research of Catalonia (ICIQ), the Barcelona Institute of Science and Technology, Avinguda Paisos Catalans 16, 43007, Tarragona (Catalonia, Spain). jlloret@iciq.es

c) Catalan Institution for Research and Advanced Studies (ICREA), Passeig Lluïs Companys, 23, 08010, Barcelona (Spain).

d) Université Grenoble Alpes, CEA, CNRS, LCBM, pmb, F-38000 Grenoble, France 


\section{ABSTRACT}

The nature of the oxidizing species in water oxidation reactions with chemical oxidants catalyzed by $\alpha$-[Fe(OTf $\left.)_{2}(\mathrm{mcp})\right]\left(\operatorname{mcp}=N, N^{\prime}\right.$-dimethyl- $N, N^{\prime}$-bis(pyridin-2ylmethyl)cyclohexane-1,2-diamine, OTf = trifluoromethanesulfonate anion), (1 $\alpha)$ and $\beta$ $\left[\mathrm{Fe}(\mathrm{OTf})_{2}(\mathrm{mcp})\right],(\mathbf{1} \boldsymbol{\beta})$ has been investigated. Mössbauer spectroscopy provides definitive evidence that $1 \alpha$ and $\mathbf{1} \beta$ generate oxoiron(IV) species as the resting state. Decomposition paths of the catalysts have been investigated by identifying and quantifying ligand fragments that form upon degradation. This analysis correlates the water oxidation activity of $1 \alpha$ and $1 \beta$ with stability against oxidative damage of the ligand via aliphatic $\mathrm{C}-\mathrm{H}$ oxidation. The site of degradation and the relative stability against oxidative degradation is shown to be dependent on the topology of the catalyst. Furthermore, the mechanisms of catalyst degradation have been rationalized by computational analyses, which also explain why the topology of the catalyst enforces different oxidation sensitive sites. This information has served for creating catalysts where sensitive $\mathrm{C}-\mathrm{H}$ bonds have been replaced by C-D bonds. Deuterated analogs, $\left.\mathrm{D}_{4-\alpha-}-\mathrm{Fe}(\mathrm{OTf})_{2}(\mathrm{mcp})\right]\left(\mathbf{D}_{4-1}-\boldsymbol{1}\right), \mathrm{D}_{4-}-\beta-$ $\left[\mathrm{Fe}(\mathrm{OTf})_{2}(\mathrm{mcp})\right]\left(\mathbf{D}_{4}-\mathbf{1} \boldsymbol{\beta}\right)$ and $\mathrm{D}_{6}-\beta-\left[\mathrm{Fe}(\mathrm{OTf})_{2}(\mathrm{mcp})\right]\left(\mathbf{D}_{6}-\mathbf{1} \boldsymbol{\beta}\right)$ were prepared, and their catalytic activity has been studied. $\mathbf{D}_{\mathbf{4}}-\mathbf{1} \boldsymbol{\alpha}$ proves to be an extraordinarily active and efficient catalyst (up to $91 \%$ of $\mathrm{O}_{2}$ yield); it exhibits initial reaction rates identical to its protio analogue, but it is substantially more robust towards oxidative degradation and yields more than 3400 TON $\left(n\left(\mathrm{O}_{2}\right) / \mathrm{n}(\mathrm{Fe})\right)$. Altogether evidence that the water oxidation catalytic activity is performed by a well-defined coordination complex and not by iron oxides formed after oxidative degradation of the ligands. 


\section{INTRODUCTION}

Water oxidation (WO) is one of the key components of natural photosynthesis and is regarded as one of the most challenging reactions to be mastered towards the development of an artificial version. The reaction is also of particular interest from a fundamental perspective because of its multi-electron and proton nature. Elucidation of the chemical aspects that govern the formation and lysis of the O-Obond, and the nature of the species involved in this reaction have also interesting derivations in the fields of oxidation catalysis and bioinorganic chemistry. Mechanistic understanding of WO reactions very much benefits from the study of molecular catalysts that operate under homogeneous conditions. ${ }^{1}$ However, proving the nature of the catalytic species is often a non-trivial question. ${ }^{2} \mathrm{WO}$ reactions involve highly oxidizing species that compromise the stability of molecular catalysts via oxidative damage. ${ }^{3}$ This issue is especially important in the case of coordination compounds and organometallic complexes bearing organic ligands. ${ }^{2 \mathrm{~d}, 4}$ Oxidation of the precatalysts may produce novel discrete complexes that can be also active catalysts under homogeneous conditions. However, in a number of cases, initial oxidation of the molecular precatalysts can result in the formation of metal-oxide(hydroxide) nanoparticles, which may be also active WO catalysts. In some cases, WO may occur via parallel paths originating from molecular catalysts operating in a homogeneous regime, and metal-oxide nanoparticles that act as heterogenous catalysts. In these cases, elucidation of the active species becomes very complicate.

Homogeneous and heterogeneous catalysts for WO based in first row transition metal (FRTM) ions attract major interest because of the earth abundant nature of these metals, which makes them potentially suitable for use in large scale. ${ }^{5}$ Furthermore, the decisive role of $\mathrm{Mn}$ in the oxygen evolving complex (OEC) of PSII highlights the viability of the WO reaction at relatively complex, potentially labile and fragile structures based in FRTM ions. In a general sense, WO at manganese centers has served as general inspiration for catalyst design. Nevertheless, FRTM complexes are generally believed to be particularly sensitive to the oxidative and usually acidic conditions operating in water oxidation reactions. The usually labile nature of metal-ligand bonds for this class of compounds is believed to critically undermine their ability to act as long-lasting WO catalysts, and there is a rich and lively debate on the exact nature of the species 
responsible for the catalytic activity. Iron coordination complexes based on aminopyridine ligands have been explored as WO catalysts employing chemical, electrochemical and photochemical conditions. ${ }^{6}$ Studies described so far have shown that the nature of the active species appears to be dependent on the nature of the catalysts, the oxidant and also the reaction conditions. The pair of catalysts $\alpha$ $\left[\mathrm{Fe}(\mathrm{OTf})_{2}(\mathrm{mcp})\right] \quad\left(\mathrm{mcp}=N, N^{\prime}\right.$-dimethyl- $N, N^{\prime}$-bis(pyridin-2-ylmethyl)cyclohexane-1,2diamine, OTf $=$ trifluoromethanesulfonate anion), $(\mathbf{1} \boldsymbol{\alpha})$ and $\boldsymbol{\beta}-\left[\mathrm{Fe}(\mathrm{OTf})_{2}(\mathrm{mcp})\right],(\mathbf{1} \boldsymbol{\beta})$ are interesting because being topological isomers, they exhibit very important differences in their catalytic activity. ${ }^{6 a, c} \mathbf{1} \alpha$ is a particularly efficient WO catalyst when employing chemical oxidants such as cerium ammonium nitrate (CAN) and $\mathrm{NaIO}_{4}$ under acidic conditions, but it rapidly degrades under photochemical and or basic conditions. ${ }^{6 a, e}$ In acidic aqueous solution, in the absence of an oxidant, it also undergoes slow hydrolytic decomposition, a behavior that can be traced to the lability of the high spin ferrous center. ${ }^{7}$ On the other hand, the isomerically related $\mathbf{1} \beta$ is poorly active with chemical oxidants and it is very rapidly degraded under acidic conditions.

The reaction mechanism proposed for these catalysts operating in acidic media with chemical oxidants such as CAN is shown in figure 1 and entails subsequent oxidation of the ferrous complexes, forming $\mathrm{Fe}^{\mathrm{IV}}(\mathrm{O})$ species which constitute the resting state during catalysis. ${ }^{6 b, 8}$ Reaction with $\mathrm{Ce}^{\mathrm{IV}}$ generates a $\mathrm{Fe}^{\mathrm{IV}}-\mathrm{O}-\mathrm{Ce}^{\mathrm{IV}}$ complex, which has been spectroscopically characterized by a combination of UV-Vis, resonance Raman and high resolution mass-spectrometry (HRMS) ${ }^{6 a}$ Similar M-O-Ce adducts ( $\mathrm{M}=\mathrm{Ru}$ and $\mathrm{Ir}$ ) have been also proposed. ${ }^{9}$ These species can be regarded as an inner-sphere electron transfer (ET) intermediate in the path towards the 1e- oxidation of the iron center. Thus, it evolves into the formation of a highly electrophilic $\mathrm{Fe}^{\mathrm{V}}(\mathrm{O})(\mathrm{OH})$ reactive species and $\mathrm{Ce}^{\mathrm{III}}$. Computational analyses indicate that $\mathrm{Fe}^{\mathrm{V}}(\mathrm{O})(\mathrm{OH})$ oxidizes the water molecule via a nucleophilic attack of the later over the terminal oxo ligand, assisted by an initial coordination of the reactive water molecule to the cis- hydroxide ligand.,10 


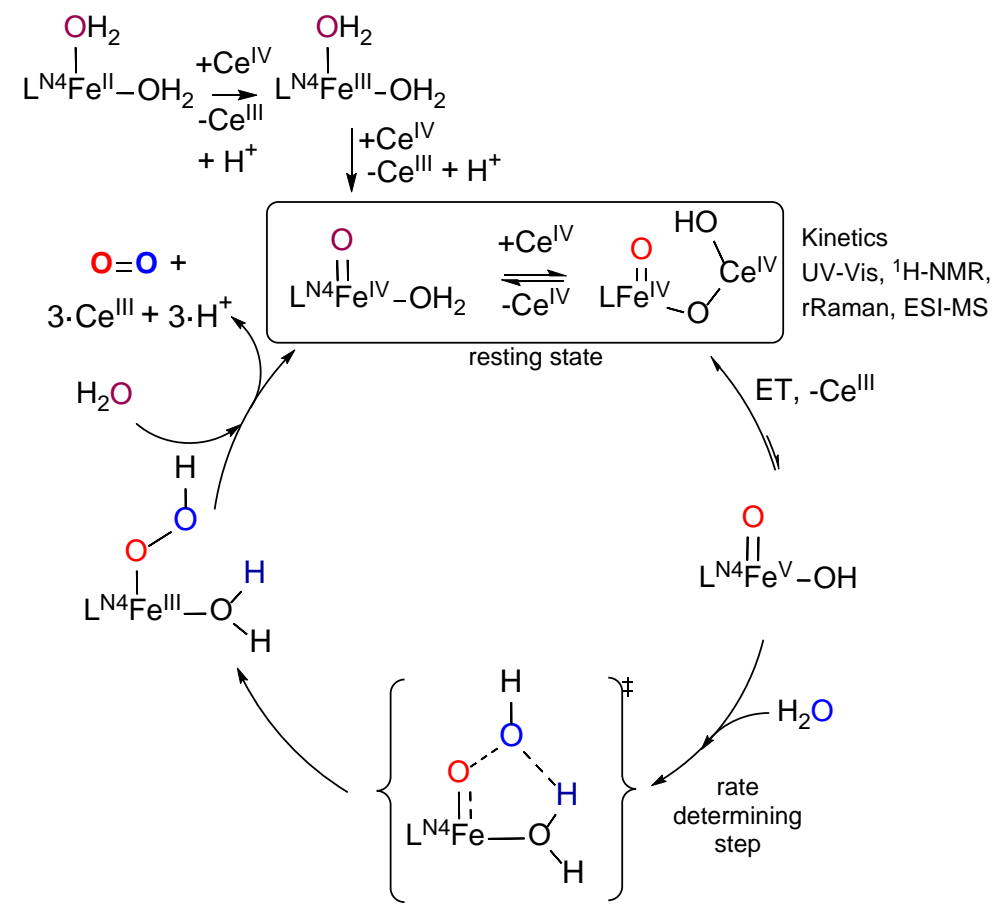

Figure 1. Reaction mechanism proposed for iron aminopyridine complexes operating in acidic media with chemical oxidants such as CAN. ${ }^{6 a}$

Despite there is a body of experimental evidence that supports this mechanistic proposal, ${ }^{\text {a a }}$ the molecular nature of the catalysts has been questioned on the basis of the observation that structurally related iron complexes undergo rapid decomposition. ${ }^{11}$ Furthermore, Mössbauer analysis that could provide unambiguous evidence for the formation of high valent iron oxo species in any molecular catalyst has not been described so far. In this scenario, stablishing the nature of the catalyst resting state and comprehension of the nature of the deactivation processes can provide definitive evidence for the molecular nature of the catalysts, but also can provide clues to rationally design novel generations exhibiting improved activity.

With these considerations in mind, in this work we have characterized by Mössbauer spectroscopy the resting state of the catalysts $1 \alpha$ and $1 \beta$ in water oxidation reactions with chemical oxidants, and we have studied their decay paths by a combination of experimental and computational methods. Ligand oxidation sensitive sites have been identified. This knowledge has served to design extraordinarily robust catalysts by deuteration of these sites, overall providing compelling evidence that WO under these 
conditions takes place via molecular, high valent oxo-iron species. We envision that the current methodology may serve as a general strategy to prove the molecular nature of oxidation catalysts.
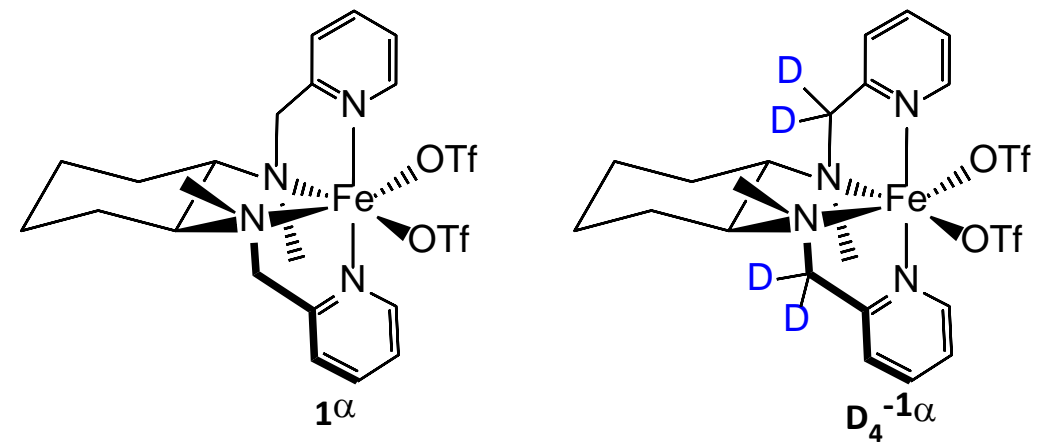

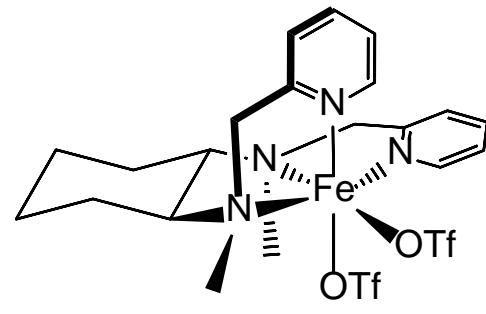

$1_{\beta}$

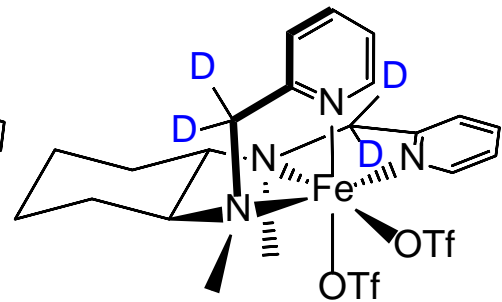

$\mathrm{D}_{4}{ }^{-1} \beta$

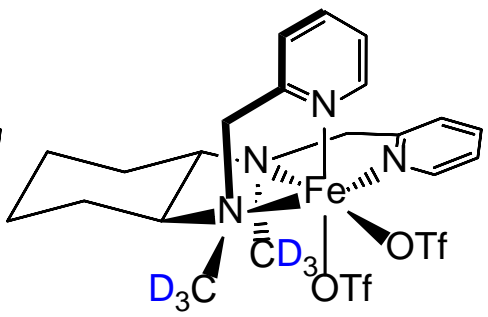

$D_{6}^{-1} \beta$

Figure 2. Iron complexes evaluated in this study.

\section{RESULTS}

Spectroscopic characterization of $\mathrm{Fe}^{\mathrm{IV}} \mathrm{O}$ species in catalytic oxidations. The pair of complexes $1 \alpha$ and $1 \beta$ catalyze water oxidation using $\mathrm{NaIO}_{4}$ or $\mathrm{CAN}$ as oxidant. ${ }^{6 a}$ High valent oxo-iron species $\alpha-\left[\mathrm{Fe}^{\mathrm{IV}}(\mathrm{O})\left(\mathrm{H}_{2} \mathrm{O}\right)(\mathrm{mcp})\right]^{2+}(2 \alpha)$ and $\beta-\left[\mathrm{Fe}^{\mathrm{IV}}(\mathrm{O})\left(\mathrm{H}_{2} \mathrm{O}\right)(\mathrm{mcp})\right]^{2+}(2 \beta)$ are proposed to be the resting state in these reactions on the basis of their distinctive UVVis spectra $\left(\lambda_{\max }=769 \mathrm{~nm}, \varepsilon=270 \mathrm{M}^{-1} \mathrm{~cm}^{-1}\right.$ for $2 \alpha ; \lambda_{\max }=778 \mathrm{~nm}, \varepsilon=280 \mathrm{M}^{-1} \mathrm{~cm}^{-1}$ for $\left.2 \beta\right)$, ESI-MS spectra $\left(\mathrm{m} / \mathrm{z}=413.162 \pm 0.003\right.$ assigned to $\left[\mathrm{Fe}^{\mathrm{IV}}(\mathrm{O})(\mathrm{OH})(\mathrm{mcp})\right]^{+}$, in $\mathrm{H}_{2}{ }^{18} \mathrm{O}$ and $\mathrm{D}_{2} \mathrm{O}$ $a+4$ and a +1 shifts observed, respectively) and by resonance Raman in the case of $2 \alpha$ $\left(\lambda_{\text {exc }}=413.1 \mathrm{~nm}, 822 \mathrm{~cm}^{-1}\right.$, downshifted by $40 \mathrm{~cm}^{-1}$ with the use of $\left.\mathrm{H}_{2}{ }^{18} \mathrm{O}\right) \cdot{ }^{6 a}$ However, a Mössbauer analyses that could unambiguously prove the high oxidation state nature of the iron center could not be obtained. We note in passing that high valent iron oxo species are also considered as the water oxidizing agents in several coordination complexes, including mononuclear and polynuclear examples, but in none of these cases has Mössbauer evidence been obtained. ${ }^{6 a-g, 61, n, r, 8,12}$ Interestingly, spectroscopic evidence 
has been built supporting the implication of high valent iron oxo species in water oxidation reactions by iron containing materials such as hematites and oxo(hydroxide)NiFe oxides. ${ }^{13}$ Notably, Mössbauer characterization of a $\mathrm{Fe}^{\mathrm{IV}}$ intermediate has been recently obtained in operando analysis of $\mathrm{NiFe}$ and $\mathrm{Fe}$ oxyhydroxide electrocatalysts. ${ }^{14}$ Frozen solutions of putative $2 \boldsymbol{\alpha}$ and $2 \boldsymbol{\beta}$, stored under liquid $\mathrm{N}_{2}$ few days before Mössbauer analysis is conducted, showed instead spectra characteristic of mononuclear ferric complexes (see SI section 8). Reasoning that the complexes may undergo slow degradation even in $\mathrm{N}_{2}$-frozen solution, we generated $2 \alpha$ and $2 \beta$ by reaction of $1 \alpha$ and $\mathbf{1} \beta$ dissolved in (acidic) water with 1.2 equiv of $\mathrm{NaIO}_{4}$, and the corresponding frozen solutions were immediately subjected to Mossbauer analysis. The corresponding Mössbauer spectra look very much alike (Figure 3) with a central doublet centered near $\delta=0.0 \mathrm{~mm} \mathrm{~s}^{-1}$ flanked by contributions extending over a large velocity range $\left(\mathrm{ca}-8\right.$ to $\left.+8 \mathrm{~mm} \mathrm{~s}^{-1}\right)$. These spectra suggest the presence of a mixture of $\mathrm{Fe}^{\mathrm{IV}}$ and $\mathrm{Fe}^{\mathrm{III}}$ species, what was confirmed by experiments conducted at $4.5 \mathrm{~K}$ under weak $(0.06 \mathrm{~T})$ and strong $(7 \mathrm{~T})$ magnetic fields applied parallel to the $\gamma$-rays (Figure SI. 43). The latter spectra could be nicely simulated with hyperfine parameters classical for both type of species (Table SI.8). ${ }^{15}$ In particular, the parameters obtained for the central doublets characterize $2 \boldsymbol{\alpha}$ and $2 \boldsymbol{\beta}$ as bona fide $\mathrm{S}=1 \mathrm{Fe}^{\mathrm{IV}}=\mathrm{O}$ species (Table SI.9). These complexes are not stable on the long run and decay rapidly to Fe ${ }^{\mathrm{III}}$ species (Figure SI.43 and 44). In this respect it is worth noting that these Mössbauer data indicate that $2 \alpha$ is significantly more stable than $\mathbf{2 \beta}$, as judged both from the higher amount of $\mathrm{Fe}^{\mathrm{IV}}$ present in the original sample (ca $60 \%$ for $2 \boldsymbol{\alpha}$ vs ca $40 \%$ for $\mathbf{2} \beta$ ) and its slower rate of the decay (Figure SI.43 and 44).

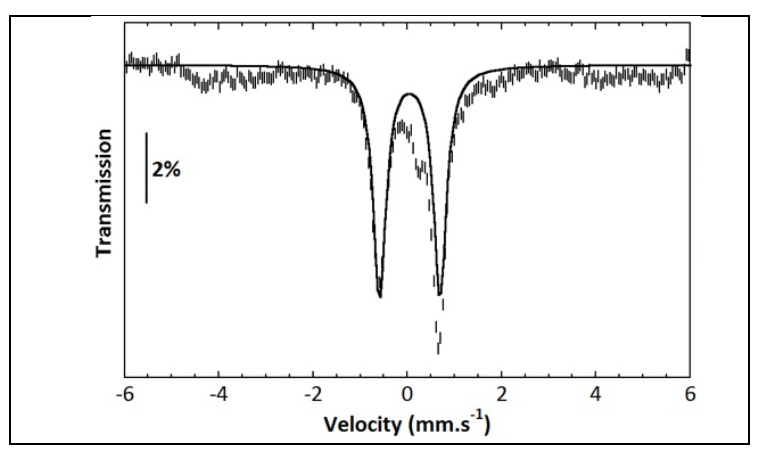




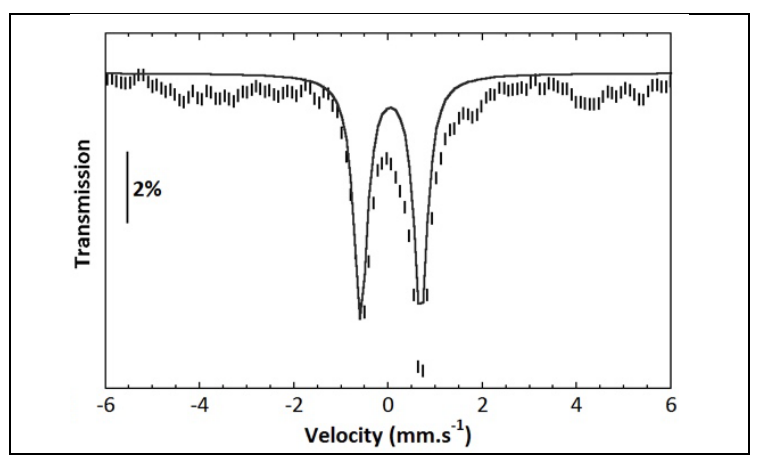

Figure 3. Mössbauer spectra of $2 \alpha$ (top) and $2 \beta$ (bottom) at $80 \mathrm{~K}$ hatched bars: experimental spectrum; solid line simulation with the parameters given in Table SI.8. Selected parameters; $2 \alpha ; \delta=0.04 \mathrm{~mm} \cdot \mathrm{s}^{-1}, \Delta \mathrm{EQ}_{\mathrm{Q}}=1.28 \mathrm{~mm} \mathrm{~s}^{-1}, \Gamma=0.20, \eta=0.43, \mathrm{~A}_{\mathrm{x}}=-29.5$, $\mathrm{A}_{y}=-16.3, \mathrm{~A}_{z}=-9.5 .2 \beta ; \delta=0.04 \mathrm{~mm} \cdot \mathrm{s}^{-1}, \Delta \mathrm{EQ}_{\mathrm{Q}}=1.28 \mathrm{~mm} \mathrm{~s}^{-1}, \Gamma=0.15, \eta=0.86, \mathrm{~A}_{x}=-25.5, \mathrm{~A}_{\mathrm{y}}$ $=-13.7, \mathrm{~A}_{\mathrm{z}}=-8.5$.

Formation and decay of oxoiron(IV) species under slight excess of oxidant. It has been previously described that water oxidation by $1 \alpha$ and $1 \beta$ with chemical oxidants is sustained as long as the putative $\mathrm{Fe}^{\mathrm{IV}}(\mathrm{O}) \mathrm{L}^{\mathrm{N} 4}$ species (where $\mathrm{L}^{\mathrm{N} 4}$ is a tetradentate aminopyridyl ligand such as mcp), considered to be the resting state on the basis of UVvis and ESI-MS monitoring, are present in the reaction mixture. ${ }^{\text {aa-c }}$ The Mössbauer characterization of $2 \alpha$ and $2 \beta$ provides strong reliability to this proposal. Thus, decomposition of $\mathrm{Fe}^{\mathrm{IV}}(\mathrm{O}) \mathrm{L}^{\mathrm{N} 4}$ is linked with depletion of catalytic activity. It can therefore be considered that identification of the decay paths of $2 \alpha$ and $2 \beta$ will be useful in designing more robust catalysts.

Towards this end, decay of $2 \alpha$ and $2 \beta$ under aqueous acidic conditions of relevance to catalytic water oxidations were first analyzed. $2 \alpha\left(1 \mathrm{mM}, \mathrm{pH}=1,25^{\circ} \mathrm{C}\right)$ was generated by oxidizing $1 \alpha$ with CAN (2.5-3 eq.). The intermediate, generated following this procedure, proved to be unstable, as shown by UV-Vis spectroscopy, in particular by monitoring of the decay of the characteristic NIR band of the complex (Figure $4 a, \lambda=$ $\left.769 \mathrm{~nm}, \varepsilon=270 \mathrm{M}^{-1} \mathrm{~cm}^{-1}, \mathrm{t}_{1 / 2}=0.15 \mathrm{~h}\right)$. Under the same conditions, the oxidation of $\mathbf{1} \beta$ produces $2 \beta$, characterized by a lower energy $\mathrm{d}$-d band $\left(\lambda=778 \mathrm{~nm}, \varepsilon=280 \mathrm{M}^{-1} \mathrm{~cm}^{-1}\right)$. Noticeable, $2 \beta$ exhibits a shorter half-life than $1 \alpha\left(\mathrm{t}_{1 / 2}=0.11 \mathrm{~h}\right.$, see figure SI.16). 
After complete decay of $2 \alpha$ and $2 \beta$, no traces of $\mathrm{O}_{2}$, or $\mathrm{CO}_{2}$ (in the gas phase, measured by GC-TCD and manometry) or $\mathrm{H}_{2} \mathrm{O}_{2}$ (in solution, measured by titration with the peroxotitanyl method $)^{16}$ were detected. Hence we can discard that the decay of $2 \alpha$ and $2 \beta$ involves; a) reaction of $2 \alpha$ and $2 \beta$ with $\mathrm{H}_{2} \mathrm{O}$ to form the $\mathrm{O}-\mathrm{O}$ bond (reaction 1 ), and b) $\mathrm{O}-\mathrm{O}$ bond formation by interaction of two units of $\mathrm{Fe}^{\mathrm{IV}}=\mathrm{O}$ (reaction 2).

$$
\begin{gathered}
\mathrm{Fe}^{\mathrm{IV}}=\mathrm{O}+\mathrm{OH}_{2} \rightarrow \mathrm{Fe}^{\mathrm{II}}+\mathrm{HO}-\mathrm{OH} \\
2 \mathrm{Fe}^{\mathrm{IV}}=\mathrm{O} \rightarrow \mathrm{Fe}^{\mathrm{III}}-\mathrm{O}-\mathrm{O}-\mathrm{Fe}^{\mathrm{III}} \rightarrow 2 \mathrm{Fe}^{\mathrm{II}}+\mathrm{O}_{2}
\end{gathered}
$$

CSI-HRMS analyses of the reaction mixtures formed after decay of $2 \alpha$ (Figure $4 b$ ) display major ion peaks corresponding to mononuclear Fe ${ }^{\mathrm{III}}$ species (in deuterated water solution, $\left[\mathrm{Fe}^{\mathrm{III}}(\mathrm{OD})_{2}(\mathrm{mcp})\right]^{+}, \mathrm{m} / \mathrm{z}=416.1848 ;\left[\mathrm{Fe}^{\mathrm{II}}(\mathrm{OD})\left(\mathrm{CF}_{3} \mathrm{SO}_{3}\right)(\mathrm{mcp})\right]^{+}, \mathrm{m} / \mathrm{z}=547.1278$; $\left.\left[\mathrm{Fe}^{\mathrm{III}}(\mathrm{OD})(\mathrm{mcp})\right]^{2+}, \mathrm{m} / \mathrm{z}=199.0891\right)$ together with partial ligand fragmentation ([mcp+O$2 \mathrm{H})+\mathrm{D}]^{+}, \mathrm{m} / \mathrm{z}=340.225$ and $\left.\left[\mathrm{mcp}-\mathrm{CH}_{2} \mathrm{py}+2 \mathrm{D}\right]^{+}, \mathrm{m} / \mathrm{z}=236.210\right)$.

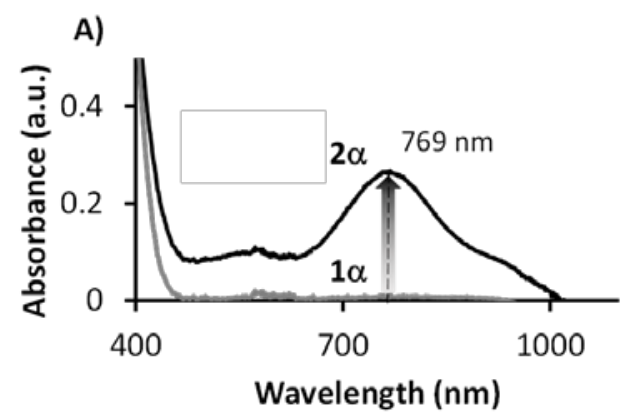

C)

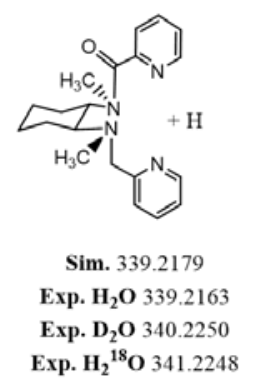

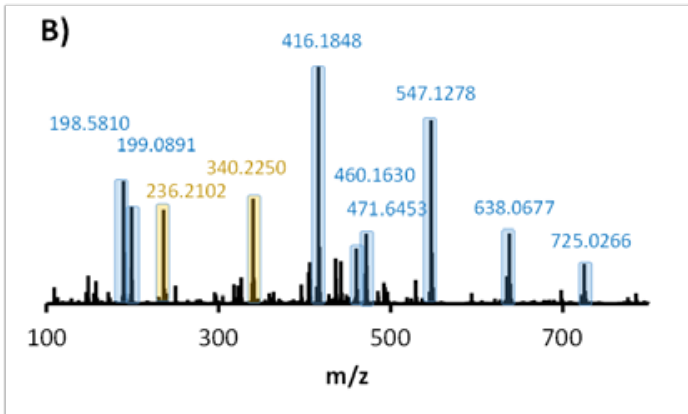

D)

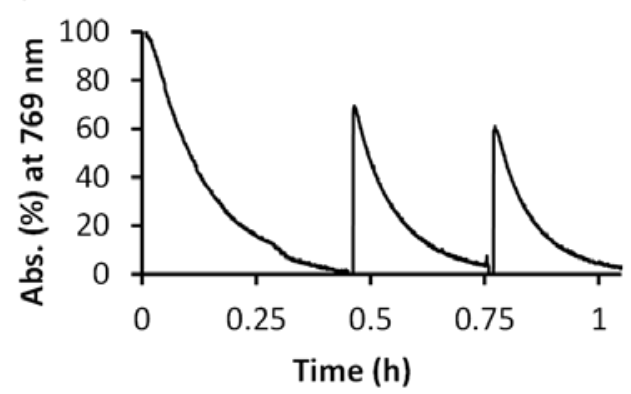

Figure 4. A) UV-Vis spectrum of $2 \alpha$ (black) in water formed by reaction of $\mathbf{1} \alpha$ (gray) (1 $\mathrm{mM}$ ) with 3 eq. of CAN in HOTf (final $\mathrm{pH}=1,25^{\circ} \mathrm{C}$ ) and B) CSI-HRMS recorded 1.5 hour after of the addition of CAN (3 eq., $50 \mu \mathrm{L})$ to $1 \alpha(4.5 \mathrm{mM}, 0.5 \mathrm{~mL})$ in $\mathrm{D}_{2} \mathrm{O}$. Blue peaks correspond to iron species while brown peaks correspond to ligand fragments. C) Ligand fragmentation observed by CSI-HRMS in reactions performed in $\mathrm{H}_{2} \mathrm{O}, \mathrm{D}_{2} \mathrm{O}$ and 
$\mathrm{H}_{2}{ }^{18} \mathrm{O}$. D) Evolution of the $2 \alpha$ chromophore monitored at $769 \mathrm{~nm}$ after the addition of 1 eq. of CAN (x 3 times).

The observation that ferric species with the intact ligand dominate the spectra suggests that $2 \alpha$ may be regenerated upon further oxidation. Indeed, after its full decay (ca. $0.8 \mathrm{~h}$, judged by UV-Vis, Figure $4 \mathrm{~d}$ ), $2 \alpha$ could be recovered up to $70 \%$ (according to the intensity of the $\lambda=769 \mathrm{~nm}$ band) by adding just one equivalent of CAN. The same procedure applied to $2 \beta$ revealed that only $50 \%$ of the oxo-Fe(IV) intermediate could be reformed by addition of one equivalent of CAN (see SI section 4 ). Thus, $2 \boldsymbol{\beta}$ decays and irreversibly decomposes faster than $2 \alpha$.

Following decay of $2 \beta$ and $2 \alpha$, reaction mixtures were treated with $\mathrm{NaOH}$ to induce complete demetalation. Subsequent extraction with an organic solvent permitted to isolate the ligand and organic products arising from its oxidative degradation. Interestingly, ESI-MS analysis of the extracted mixtures (Figure 5), revealed that the major ligand oxidation fragments obtained after the decay of $2 \alpha$ and $2 \beta$ are different. In the case of $2 \alpha$, ligand fragments arise from the breakage of the pyridylmethyl arm presumably initiated through oxidation of the benzylic methylene site (339.21 $\left(\left[\mathrm{C}_{20} \mathrm{H}_{26} \mathrm{~N}_{4} \mathrm{O}\right]+\mathrm{H}^{+}\right)$and $234.19 \mathrm{~m} / \mathbf{z}\left(\left[\mathrm{C}_{14} \mathrm{H}_{23} \mathrm{~N}_{3}\right]+\mathrm{H}^{+}\right)$assigned to $[\mathbf{m c p}(+\mathbf{O}-\mathbf{2} \mathbf{H})]+\mathbf{H}^{+}$and $\left[\mathbf{m c p}-\mathrm{CH}_{2} \mathbf{P y}+\mathbf{H}\right]+\mathbf{H}^{+}$, respectively, depicted in Figure 5a). Instead, the main peak observed after decay of $2 \beta$ (Figure $5 b$ ) results from the loss of a methyl group, presumably through oxidation of the $\mathrm{N}$-methyl position $\left(311.22 \mathrm{~m} / \mathrm{z}\left(\left[\mathrm{C}_{19} \mathrm{H}_{26} \mathrm{~N}_{4}\right]+\mathrm{H}^{+}\right)\right.$ assigned to $[\mathbf{m c p}(-\mathbf{M e}+\mathbf{H})]+\mathbf{H}^{+}$, depicted in Figure $\left.4 \mathrm{c}\right)$. Oxygenation of a methylenic site $(\mathrm{m} / \mathrm{z}=339.21)$ is also observed as a minor path. Thus, this analysis suggests that $2 \beta$ and $2 \alpha$ decay via different paths. Since $2 \alpha$ and $2 \beta$ are topological isomers, it can be concluded that the particular tridimensional arrangement of the ligand in these coordination complexes define specific decay paths. 

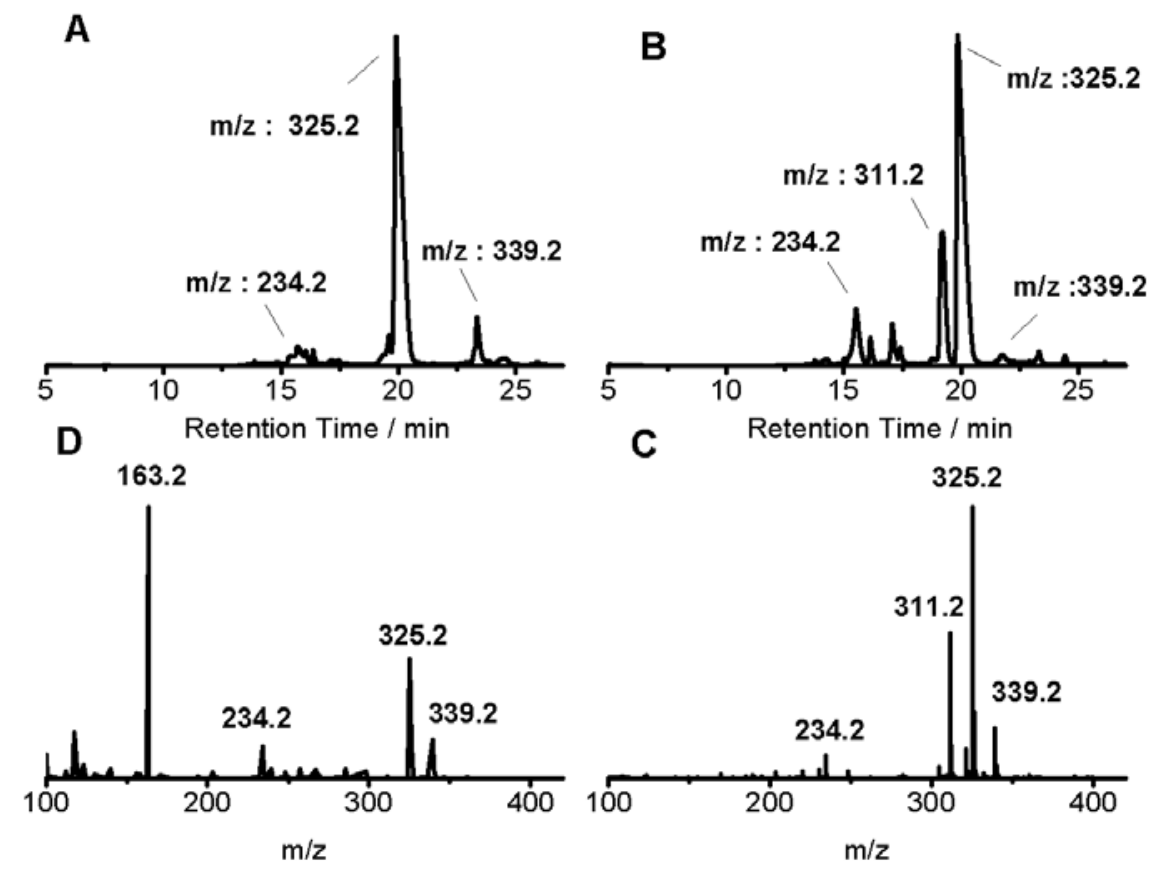

Figure 5. Top: HPLC chromatograms of the extracted ligand fragments after complete decay and demetalation of oxoiron(IV) complexes $2 \alpha$ (panel $\mathbf{A}$ ) and $\mathbf{2} \beta$ (panel B), see supporting information for details of the ligand extraction procedures. $2 \alpha$ and $2 \beta$ were generated by reacting $1 \alpha$ or $1 \beta(1 \mathrm{mM})$ with CAN ( $3 \mathrm{mM})$. The absorbance detection was performed at $247 \mathrm{~nm}$, coinciding with the maximum absorption of the pyridine chromophore. Bottom: HRMS spectra of the extracted decay mixture of $1 \alpha$ or $\mathbf{1} \beta$ ( $1 \mathrm{mM}$, respectively panels $\mathbf{C}$ and D) with $\mathrm{CAN}(3 \mathrm{mM})$ recorded in $\mathrm{CHCl}_{3}$ at $298 \mathrm{~K}$. The observed peaks can be assigned to ligand oxidation fragments, as follow: m/z: 234.2 fragment [mcp- $\left.\mathrm{CH}_{2} \mathrm{Py}\right] \mathrm{H}^{+}$(chemical formula: $\mathrm{C}_{14} \mathrm{H}_{24} \mathrm{~N}_{3}$ ); m/z: 163.2 fragment [mcp] $2 \mathrm{H}^{+}$ (chemical formula: $\mathrm{C}_{20} \mathrm{H}_{30} \mathrm{~N}_{4}$ ); m/z: 325.2 fragment [mcp] $\mathrm{H}^{+}$(chemical formula: $\mathrm{C}_{20} \mathrm{H}_{29} \mathrm{~N}_{4}$ ); m/z: 311.2 fragment [mcp-Me] $\mathrm{H}^{+}$(chemical formula: $\mathrm{C}_{19} \mathrm{H}_{27} \mathrm{~N}_{4}$ ) and m/z: 339.2 fragment $[\mathrm{mcp}+\mathrm{O}] \mathrm{H}^{+}$(chemical formula: $\mathrm{C}_{20} \mathrm{H}_{27} \mathrm{~N}_{4} \mathrm{O}$ ).

The identification of the oxidized fragment structures was unambiguously corroborated by performing HPLC-MS analyses of the extracted decay mixtures (Figures 4, 5 and S.I. Section 5), and by comparison of the HPLC-MS retention times with 
independently prepared samples of the presumed fragments. Moreover, the quantification of the fragments contained in the extracted residues was also performed by HPLC-MS (Figure 6). Blank experiments, applied to aqueous solutions of $1 \alpha$ and $\mathbf{1} \beta$, show that $\sim 90 \%$ of the ligand is recovered by this procedure. This analysis thus provides a detailed picture of the fate of the ligand, which in turn can be satisfactorily correlated with the decay paths of the catalysts.

In first place, HPLC-MS analyses of the extracted mixtures obtained after the initial decay of $2 \alpha$ and $2 \beta$ showed that the amount of intact ligand (mcp) is in good agreement with the percentage of oxoiron(IV) species that can be regenerated upon a second addition of oxidant ( $69 \%$ and $50 \%$ for $1 \alpha$ and $1 \beta$, respectively). This observation strongly suggests that irreversible decay of $2 \alpha$ and $2 \beta$ does not entail a hydrolytic/demetalation process, without ligand oxidation. In other words, the ligand remains ligated to the iron center and free ligand never accumulates in solution, despite of the highly acidic conditions of the reactions mixtures. The high stability of $2 \alpha$ under acidic conditions is especially notable when compared with its ferrous precursor $1 \alpha .^{7}$ This contrasting behavior can be understood by considering the respective labile and inert character of the high spin ( $\mathrm{S}=2) \mathrm{Fe}(\mathrm{II})$ and low spin (S=1) Fe(IV) complexes. Indeed, oxo-iron(IV) complexes with aminopyridine ligands are known to be remarkably stable under highly acidic conditions. ${ }^{17}$

In second place, the oxidative demethylation of a NMe group is confirmed to be the main decomposition pathway associated to $2 \beta$; in fact, the decay mixture shows that $20 \%$ of the ligand has been converted into the mcp-Me fragment $\left(\left[\mathrm{C}_{19} \mathrm{H}_{26} \mathrm{~N}_{4}\right]\right.$, figure 6). The degradation of the mcp ligand, upon decay of $2 \beta$, also occurs through oxidation at the benzylic methylenic sites, however, in a relatively minor extent $(<10 \%)$. Instead, the demethylation pathway seems to be hampered for $2 \alpha$. Only traces of the mcp-Me fragment could be detected. The major fragments obtained from the degradation of $2 \alpha$ can be rationalized to originate from the initial oxidation of the benzylic methylenic sites.

Formation and decay under excess of oxidant. When the same analysis is performed after the reaction of $1 \alpha$ and $\mathbf{1} \beta$ with $75 \mathrm{mM}$ of $\mathrm{Ce}^{\mathrm{IV}}$, conditions that are catalytically relevant for water oxidation, ${ }^{6 c}$ ligand oxidative degradation is evidenced to be more 
important (Figure 6). Importantly, the nature of the fragments observed after the water oxidation reaction, are in good agreement with the products obtained after decomposition of $2 \alpha$; about $60 \%$ of the entire mcp ligand was still recovered at the end of the reaction (judged by HPLC-MS). However, reaction of $\mathbf{1} \beta$ leads to the almost complete decomposition of the mcp ligand, and identifiable fragments account only for roughly $30-35 \%$ of the original amount of ligand. In addition, multiple minor products, presumably ligand fragments formed by multiple oxidative degradation, are observed (Figure 6).
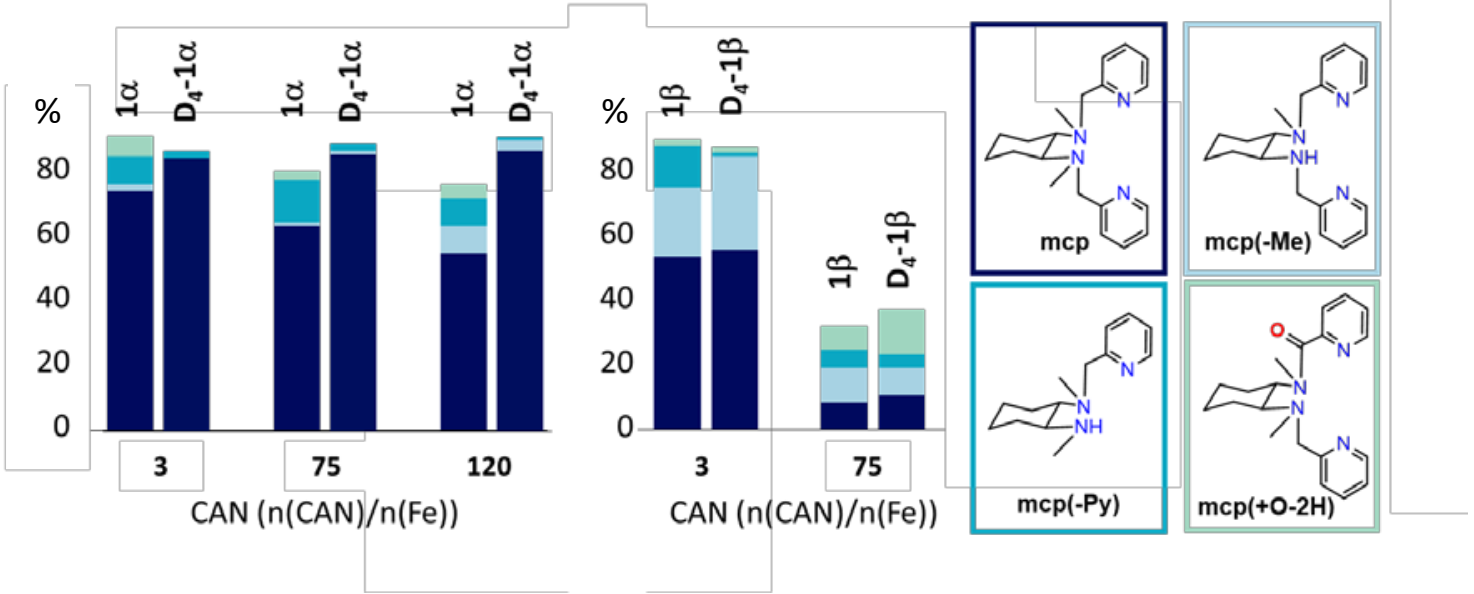

Figure 6. Quantification of the ligand degradation products (in \% respect to the theoretical amount) after reaction of $\mathbf{1} \beta, \mathrm{D}_{\mathbf{4}} \mathbf{- 1} \boldsymbol{\beta}(1 \mathrm{mM})$ in water with CAN $(3,75$ or 100 $\mathrm{mM}$ ), demetalation and ligand extraction. Ligand fragments where identified by HPLCMS and by comparison with independently prepared products. See experimental for details.

Deuteration. Ligand degradation analyses described above indicate that the pseudobenzylic methylenic C-H bonds of the mcp ligand are the most prone sites for the oxidative degradation of $1 \alpha$ and derived species under stoichiometric and catalytic conditions. This leaded us considering possible strategies for protecting/strengthening these positions. We rationalized that provided the catalyst has a molecular nature, deuteration of these sites will provide stronger $\mathrm{C}-\mathrm{H}$ bonds, while retaining the electronic and structural properties of the catalyst intact, and therefore the lifetime of the catalyst 
will be extended. Following on this reasoning, tetradeutero $\mathbf{D}_{4}-\mathbf{m c p}$ ligand was prepared by reacting mcp with $\mathrm{NaH}$ in $\mathrm{CD}_{3} \mathrm{CN}$, and the corresponding complexes $\alpha$ - $\mathrm{D}_{4}$ $\left[\mathrm{Fe}^{\mathrm{II}}\left(\mathrm{CF}_{3} \mathrm{SO}_{3}\right)_{2}(\mathrm{mcp})\right], \quad \mathbf{D}_{\mathbf{4}} \mathbf{- 1} \boldsymbol{\alpha}$, and $\beta-\mathrm{D}_{4}-\left[\mathrm{Fe}^{\mathrm{II}}\left(\mathrm{CF}_{3} \mathrm{SO}_{3}\right)_{2}(\mathrm{mcp})\right], \mathbf{D}_{\mathbf{4}} \mathbf{- 1} \boldsymbol{\beta}$, were prepared. Characterization of $\mathbf{D}_{\mathbf{4}} \mathbf{- 1} \boldsymbol{\alpha}$ and $\mathbf{D}_{\mathbf{4}} \mathbf{- 1} \boldsymbol{\beta}$, and in particular deuteration of the benzylic sites was confirmed by ${ }^{1} \mathrm{H}-\mathrm{NMR}$ spectroscopy and MS analysis (See S.I. Section 3).

Effect of deuteration in the stability of $D_{4-2} \alpha$ and in the catalytic water oxidation activity. Most gratifyingly, the simple deuteration of the pseudo-benzylic $\mathrm{CH}_{2}$ sites in $\mathbf{1} \alpha$ has a very important impact in its catalytic activity, and in the inertia of $\mathbf{D}_{\mathbf{4}} \mathbf{- 2} \boldsymbol{\alpha}$. First of all, the half-life time of $\mathrm{D}_{\mathbf{4}}-\mathbf{2} \boldsymbol{\alpha}$, generated by addition of CAN ( $3 \mathrm{mM}$ ) to a water solution of $\mathbf{D}_{4}-\mathbf{1} \alpha(1 \mathrm{mM})$, was enhanced 18-fold (monitored by UV-Vis spectroscopy) (Figure SI.14-15), from $0.15 \mathrm{~h}$ to $2.8 \mathrm{~h}$ with regard to its protio analogue. However, the deuteration of the pseudobenzylic positions does not modify the stability of $\mathbf{D}_{\mathbf{4}} \mathbf{- 2} \boldsymbol{\beta}$, which retains the same half-life of $2 \beta$ (Figure SI.16-17).

Furthermore, following decay of $D_{4-2} \alpha$ and $D_{4-2} \beta$, the decay mixtures were subjected to the standard demetalation-extraction procedures, and ligand fragments analyzed (Figure 6). In the case of $\mathbf{D}_{4}-\mathbf{2} \alpha$, the minor degradation pathway associated with the oxidation of pseudo-benzylic $\mathrm{CH}_{2}$ sites (producing $\mathbf{m c p}(-\mathbf{P y}), \mathbf{m c p}(+\mathbf{O}-\mathbf{2 H})$ ) appears to be further hampered by deuteration of these positions, and the recovery of the intact ligand increases from $69 \%(2 \alpha)$ to $79 \%\left(D_{4}-2 \alpha\right)$. Decay of $\mathbf{D}_{4}-2 \beta$ shows a different pattern. The percentage of unmodified ligand (mcp) does not change upon deuteration, but the relative amounts of products resulting from either the loss of a methylpyridine arm $(\mathbf{m c p}(-\mathrm{Py}))$ or a methyl group $(\mathbf{m c p}(-\mathbf{M e}))$ change, with the later increasing at the expenses of the former upon deuteration. This observation suggests that there is a competition between the paths leading to the two products. Deuteration does not improve the recovery of the ligand in reactions of $\mathbf{D}_{\mathbf{4}} \mathbf{- 1} \boldsymbol{\beta}$ with excess CAN (75 mM), but instead it has a favorable positive effect in $\mathbf{1} \alpha$, which is further retained when $120 \mathrm{mM}$ CAN is employed (Figure 6, Table S.I.7). In all cases, deuteration leads to almost quantitative recovery of the intact ligand $(\sim 85 \%)$, demonstrating that ligand degradation 
and demetalation for this catalyst is basically ligated to oxidation of this site, and most remarkably, the process is blocked by deuteration.

\section{Manometry and GC-MS on-line studies of the gases evolved in the chemically driven}

WO. Catalytic activity of the series of complexes, including protio and deuterio analogues was studied in parallel in order to ensure proper comparison among the series. $\mathrm{O}_{2}$ produced in the reactions was monitored by manometry and also by gas chromatography. Values determined by the two methods are in good agreement. For example, under catalytic conditions, manometric measurements indicate that $1 \alpha$ and $\mathbf{D}_{4-}$ $1 \alpha$ yield $379 \pm 3$ and $1732 \pm 90 \mathrm{TON} \mathrm{O}_{2}$, respectively (Table 1), values that are in good agreement with the values determined by GC $(403 \pm 10$ and $1896 \pm 110){ }^{6 a, c}$ Indeed, for the whole series of complexes, GC-TCD analyses of the gas at the headspace of the reactions confirmed that the gas formed is essentially $\mathrm{O}_{2}$ (Table 1).

Most remarkably, these values indicate that deuteration creates a much more active catalyst, yielding approximately a fourfold increase in TONs. The $\mathrm{O}_{2}$ produced for $\mathbf{D}_{6-} \boldsymbol{\beta}-$ $\mathbf{F e}(\mathrm{OTf})_{2}(\mathbf{m c p})\left(\mathbf{D}_{6}-\mathbf{1} \boldsymbol{\beta}\right)(161 \pm 2 \mathrm{TON} \mathrm{O})$ is also roughly fourfold increased with respect to $\mathrm{D}_{4}-\boldsymbol{\beta}-\mathrm{Fe}(\mathrm{OTf})_{2}(\mathbf{m c p}) \quad\left(\mathrm{D}_{4}-\mathbf{1} \boldsymbol{\beta}\right)$ and $\boldsymbol{\beta}-\mathrm{Fe}(\mathrm{OTf})_{2}(\mathbf{m c p}) \quad(\mathbf{1} \boldsymbol{\beta})$ (39 and $30 \mathrm{TON} \mathrm{O}_{2}$, respectively), although absolute numbers are still modest when compared with $1 \alpha$ and $D_{4}-1 \alpha$. The improved performance of $D_{6}-\mathbf{1} \beta$ can be rationalized taking into account the previous analysis of decay paths, which indicated substantial degradation of this isomer via oxidation of the $N$-methyl groups. Accordingly, deuteration of these groups in $\mathbf{D}_{\mathbf{6}} \mathbf{- 1} \boldsymbol{\beta}$ prevents its decomposition and allows for a more sustained oxygen evolution activity. None of the complexes shows induction time in their catalytic activity. In addition, it is particularly noticeable that $\mathbf{D}_{4}-1 \alpha$ and $1 \alpha$ have the same initial rate for oxygen evolution (See Figure $8 \mathrm{a}, \mathrm{b}$ ). This has important mechanistic implications since the metal center in both $D_{4}-1 \alpha$ and $1 \alpha$ complexes experience the same electronic and steric properties. Equivalent $\mathrm{O}_{2}$ evolution rates strongly evidences catalytic species only differing on the isotopic nature of the pseudobenzylic positions. Iron complexes containing as ligands different degradation fragments of the mcp ligand (See Figure 7) were prepared and their activity as water oxidation catalysts was tested. These complexes do not show 
appreciable water oxidation catalytic activity. In addition, iron complexes where the methyl groups of the mcp ligand are replaced by protons or with the two pyridyl positions oxidized are also catalytically incompetent. ${ }^{18}$ Therefore, the initial $\mathrm{O}_{2}$ evolution should came from the intact species before degradation. Altogether strongly indicates the molecularity of the catalytic system and that the original molecular complex is the active species. The same trend was observed for the pair $\mathbf{1} \boldsymbol{\beta}$ and $\mathbf{D}_{4} \mathbf{- 1} \boldsymbol{\beta}$ but they are somewhat different for $\mathbf{D}_{6}-\mathbf{1} \boldsymbol{\beta}$. Presumably, initial rates measured for $\mathbf{1} \boldsymbol{\beta}$ and $\mathbf{D}_{\mathbf{4}} \mathbf{- 1} \boldsymbol{\beta}$ are already contaminated by rapid catalyst degradation (Table 1 entries 8-10 and Figure 8 and SI.45).
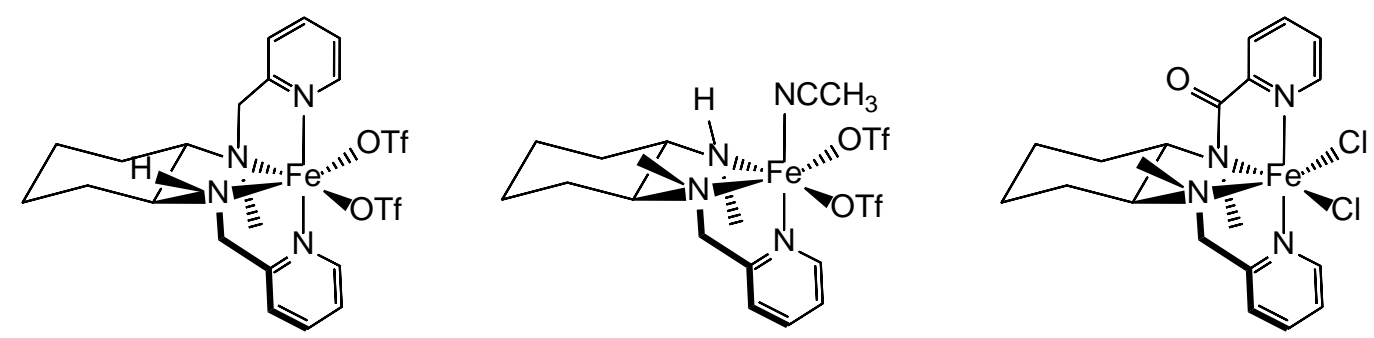

Figure 7. Iron complexes of the fragmented ligands, tested under standard water oxidation catalysis conditions.

Table 1. Water oxidation catalytic activities for the studied iron complexes.

\begin{tabular}{|c|c|c|c|c|c|c|c|c|}
\hline Entry & Complex & $\begin{array}{l}\text { [CAN] } \\
(\mathrm{mM})\end{array}$ & $\begin{array}{l}\text { [Cat] } \\
(\mu \mathrm{m})\end{array}$ & $\begin{array}{l}\text { TOF } \\
\left(h^{-1}\right)^{a}\end{array}$ & $\mathrm{TON} \mathrm{O} 2^{\mathrm{a}}$ & $\mathrm{TON} \mathrm{O}_{2}{ }^{\mathrm{b}}$ & $\begin{array}{c}\text { Yield } \\
\mathrm{O}_{2}(\%)\end{array}$ & $\begin{array}{l}\mathrm{TON} \\
\mathrm{CO}_{2}{ }^{\mathrm{b}}\end{array}$ \\
\hline 1 & $1 \alpha F e^{c}$ & 125 & 12.5 & 850 & $379 \pm 3$ & $400 \pm 10$ & 16 & $<1$ \\
\hline 2 & $D_{4-1} \alpha F^{c}$ & 125 & 12.5 & 820 & $1730 \pm 90$ & $1900 \pm 110$ & 76 & $<1$ \\
\hline 3 & $1 \beta F e^{c}$ & 125 & 12.5 & 33 & $30 \pm 1$ & $46 \pm 1$ & 2 & $<1$ \\
\hline 4 & $D_{4}-1 \beta F e^{c}$ & 125 & 12.5 & 37 & $39 \pm 2$ & $52 \pm 3$ & 2 & $<1$ \\
\hline 5 & $D_{6}-1 \beta F e^{c}$ & 125 & 12.5 & 214 & $161 \pm 2$ & $151 \pm 2$ & 6 & $<1$ \\
\hline 6 & mcp-Me & 125 & 12.5 & - & 0 & $<1$ & - & $<1$ \\
\hline 7 & mcp-Pyc & 125 & 12.5 & - & 0 & $<1$ & - & $<1$ \\
\hline 8 & $1 \alpha \mathrm{Fe}^{\mathrm{d}}$ & 75 & 1000 & 150 & 12 & - & 64 & - \\
\hline 9 & $D_{4-1 \alpha F e^{d}}$ & 75 & 1000 & 200 & 17 & - & 91 & - \\
\hline 10 & $1 \beta F e^{d}$ & 75 & 1000 & 74 & 9 & - & 48 & - \\
\hline 11 & $1 \alpha \mathrm{Fe}^{\mathrm{e}}$ & 125 & 1 & $1470^{\mathrm{f}}$ & $700 \pm 10$ & $800 \pm 90$ & 3 & - \\
\hline 12 & $D_{4-1} \alpha F^{e}$ & 125 & 1 & $1480^{\mathrm{f}}$ & $3400 \pm 150$ & $3800 \pm 100$ & 12 & - \\
\hline
\end{tabular}


Reactions performed in MilliQ water at $25{ }^{\circ} \mathrm{C}$ under vigorously stirring. a) Results obtained by manometry studies after $20 \mathrm{~h}$ of reaction. TOF is calculated after $5 \mathrm{~min}$ of the addition of the catalyst. b) Results from the analysis of an aliquot of the head-space by GC-TCD after $20 \mathrm{~h}$ of reaction. c) Reaction conditions A: The catalyst $(0.5 \mathrm{ml}$, final concentration $12.5 \mu \mathrm{M})$ was injected through a septum into the reaction vial containing CAN aqueous solution $(9.5 \mathrm{ml}, 131 \mathrm{mM}$, final concentration $125 \mathrm{mM})$. Initial $\mathrm{pH}$ is 0.8 . d) Reaction conditions B: CAN ( $0.8 \mathrm{ml}$ of stock solution in HOTf: $\mathrm{H}_{2} \mathrm{O}$ 3:10 solution, final concentration $75 \mathrm{mM}$ ) was injected through a septum into the reaction vial containing the catalyst aqueous solution ( $3.2 \mathrm{ml}$, final concentration $1 \mathrm{mM}) \mathrm{pH}$ is 1 . e) Reaction conditions C: The catalyst $(0.5 \mathrm{ml}$, final concentration $1-3 \mu \mathrm{M})$ was injected through a septum into the reaction vial containing CAN aqueous solution $(14.5 \mathrm{ml}, 129.3 \mathrm{mM}$, final concentration $125 \mathrm{mM}$ ). TOF is calculated after $1 \mathrm{~min}$ of the addition of the catalyst. f) TOF is calculated after $200 \mathrm{sec}$. of the addition of the catalyst.
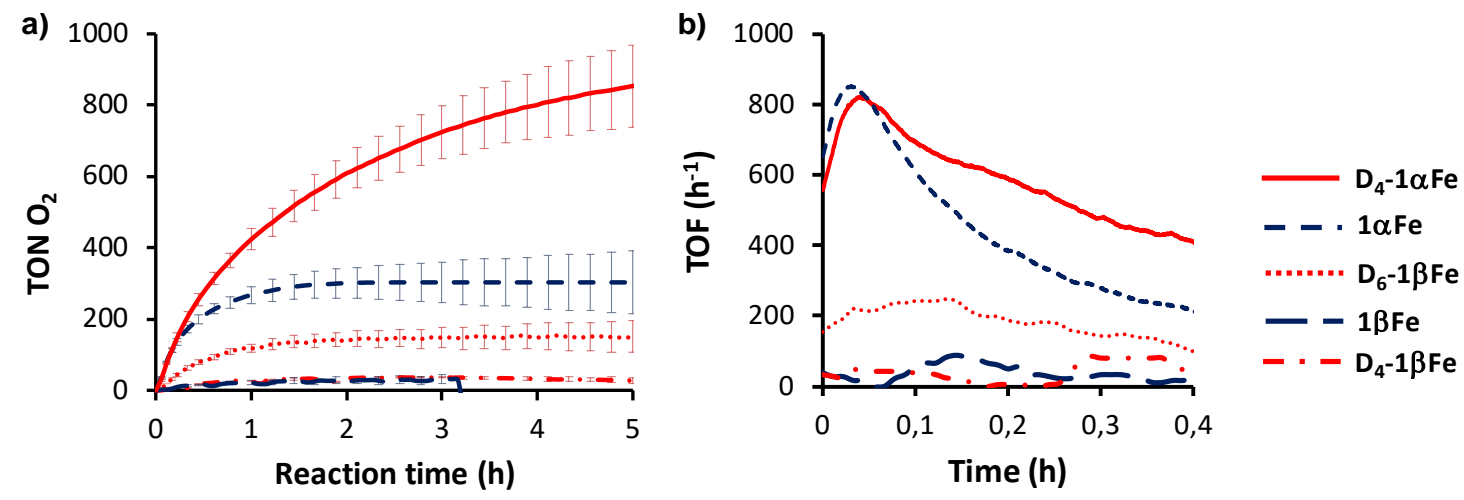

Figure 8. a) Gas traces and b) initial TOF $\left(\mathrm{h}^{-1}\right)$ of the manometry monitorization when the iron catalyst $\left(\boldsymbol{\alpha}-\mathrm{Fe}(\mathrm{OTf})_{2}(\mathrm{mcp})\right.$ (short-dashed line), $\mathrm{D}_{4-\boldsymbol{\alpha}}-\mathrm{Fe}(\mathrm{OTf})_{2}(\mathbf{m c p})$ (straight line), $\beta-F e(O T f)_{2}(\operatorname{mcp})$ (long-dashed line), $\mathbf{D}_{4}-\beta-F e(O T f)_{2}(\operatorname{mcp})$ (dotted-short-dashed line) and $\mathbf{D}_{6-\beta}-\mathbf{F e}(\mathbf{O T f})_{2}(\mathbf{m c p})$ (dotted line)) (0.5 $\mathrm{ml}$ of a stock solution, final concentration $12.5 \mu \mathrm{M}$ ) is added to a stirred solution of CAN (9.5 ml, final concentration 1000 equiv., $125 \mathrm{mM}$ ) in Milli-Q water at $25^{\circ} \mathrm{C}$ and initial $\mathrm{pH} 0.8$. Vertical lines represent the error bars from standard deviation between replicates.

Direct GC-MS online-analysis of the gases evolved at the head-space along the reaction time permits to identify relative rates for $\mathrm{O}_{2}$ and $\mathrm{CO}_{2}$ evolution from the very beginning of the reaction to hundreds of seconds. In all cases the rates for $\mathrm{O}_{2}$ evolution are much higher than the one measured for $\mathrm{CO}_{2}$ production, being the latter only produced in trace levels (Figure SI. 45. B). Thus, the measured reaction rates by manometry experiments are ascribed only to $\mathrm{O}_{2}$ evolution. Likewise, catalyst 
decomposition is not connected with $\mathrm{O}_{2}$ evolution. The sum of these results indicates that the higher activity of $\mathbf{D}_{4}-\mathbf{1} \alpha$ results from a more robust character. In combination with the HPLC analysis of the degradation paths, we can conclude that deuteration of the pseudobenzylic positions blocks the most important deactivation path, conferring stability to the catalyst.

Multiple oxidant addition experiments. The increase in TON (about 5 fold) obtained with $\mathrm{D}_{4-1} \mathbf{1} \alpha$ with respect to $1 \alpha$ nicely translates into substantially better yields of $\mathrm{O}_{2}$ produced (76\% vs 16\%). However, this 5-fold increase appears modest when comparing the 18 -fold improvement in the half-life time of $D_{4-2} \alpha$ in comparison with $2 \alpha$. Furthermore, while significant catalyst degradation is observed for $1 \boldsymbol{\alpha}$, ligand recovery experiments showed minimum degradation of $\mathbf{D}_{\mathbf{4}} \mathbf{- 1} \alpha$. This data let us to consider that the end of catalytic activity observed in $\mathbf{D}_{\mathbf{4}} \mathbf{- 1} \alpha$ does not respond to a catalyst degradation process. Further optimization by lowering the catalyst concentration yields more than $3400 \mathrm{O}_{2}$ TON $1 \mu \mathrm{M}$ (see table 1), which is about one order of magnitude higher than previously reported values with $1 \alpha$. These observations indicate that catalytic activity, at $12.5 \mu \mathrm{M}$, with the most robust catalyst of the series $\left(\mathbf{D}_{4}-\mathbf{1} \alpha\right)$ stops not as a result of catalyst degradation, but instead because of Nernstian effects in the $\mathrm{Ce}(\mathrm{IV}) / \mathrm{Ce}(\mathrm{III})$ potential. Considering the ratio of $\left[\mathrm{Ce}^{\mathrm{IV}}\right] /\left[\mathrm{Ce}^{\mathrm{III}}\right]$ at which $\mathrm{O}_{2}$ evolution stops after the first addition of CAN, we can determine a potential threshold of $1.62 \mathrm{~V} v s \mathrm{NHE}$ for catalytic activity. The same value was consistently obtained when reactions were initiated with different amounts of CAN. Noticeable, this value is in reasonable agreement with the DFT computed value $\left(1.73 \mathrm{~V}\right.$ vs NHE) for the PCET from $\left[\mathrm{Fe}^{\mathrm{IV}}(\mathrm{O})\left(\mathrm{OH}_{2}\right)(\mathrm{mep})\right]^{2+}$ to $\left[\mathrm{Fe}^{\mathrm{V}}(\mathrm{O})(\mathrm{OH})(\mathrm{mep})\right]^{2+} \quad\left(\right.$ mep $\quad=\quad N, N^{\prime}$-bis(2-pyridylmethyl)- $N, N^{\prime \prime}$-dimethyl-1,2diaminoethane), ${ }^{8}$ suggesting that access to the active $\mathrm{Fe}^{\mathrm{v}}(\mathrm{O})(\mathrm{OH})$ oxidant becomes unfavorable at this $\left[\mathrm{Ce}^{\mathrm{IV}}\right] /\left[\mathrm{Ce}^{\mathrm{III}}\right]$ ratio.

DFT modelling of the decomposition pathways. DFT calculations have been conducted to evaluate the feasibility of the methylene/methyl oxidation mechanism by $1 \alpha$ and $1 \beta$ topological isomers (see Computational details SI section 10). The geometry of the early proposed $\mathrm{Fe}^{\mathrm{v}}(\mathrm{O})(\mathrm{OH}) \mathrm{WO}$ active species, 3 was first optimized for the two topological isomers (See computational details SI. Section 10). In the case of $3 \beta$ complex, two cistautomers may exist in which the $\mathrm{Fe}=\mathrm{V}$ moiety is parallel $(3 \beta-\mathbf{a})$ or perpendicular $(3 \beta-$ 
b) to the methyl groups of the mcp ligand (Table 2). According to the free energy differences between the $\beta$ isomers, the intermediate $3 \beta$-a in the $S=3 / 2$ ground spin state is the most stable form. Thus, $3 \beta$-a was chosen to carry out the mechanistic study.

Table 2: Spin states relative free energies $\left(\mathrm{kcal} \cdot \mathrm{mol}^{-1}\right)$ of the $\mathrm{Fe}^{\mathrm{v}}(\mathrm{O})(\mathrm{OH})$ intermediates for complex $\mathbf{1} \beta$ in the two cis-tautomers $3 \beta$-a and $3 \beta$-b.

\begin{tabular}{|c|c|c|}
\hline & $3 \beta-a$ & $3 \beta-b$ \\
\hline$S=1 / 2$ & 13.0 & 15.6 \\
\hline$S=3 / 2$ & $0.0^{\mathrm{a}}$ & 2.7 \\
\hline
\end{tabular}

[a] Free energies respect to the most stable structure.

The methyl groups in $\mathbf{3} \beta-\mathbf{a}$ are close to the oxo moiety (See Fig. 9a). Therefore, it is expected that the decomposition of the mcp ligand may start with the oxidation of a $\mathrm{CH}_{3}$ group. Indeed, the $\mathrm{Fe}^{\mathrm{V}}=\mathrm{O}$ in the quartet spin state surface directly hydroxylates the $\mathrm{CH}_{3}$ with a free energy barrier of $18.7 \mathrm{kcal} \cdot \mathrm{mol}^{-1}$ with respect to $\beta-\left[\mathrm{Fe}^{\mathrm{V}}(\mathrm{O})(\mathrm{OH})(\mathrm{mcp})\right]^{2+}(3 \beta-\mathbf{a})$ species, which can be reached under catalytic conditions. ${ }^{19}$ (See SI. computational section for details) This result is in agreement with the experimentally observed methyl decomposition product. Finally, the free energy profile for the $\mathrm{O}-\mathrm{O}$ bond formation was also computed to determine if the decomposition reaction pathway prevails in solution (Figure 9). The water nucleophilic attack on the $\mathrm{Fe}^{\mathrm{V}}=\mathrm{O}$ moiety follows an stepwise mechanism, as has been described previously, ${ }^{5}$ and the $\mathrm{O}-\mathrm{O}$ bond formation event presents the highest in energy transition state $\left(\Delta \mathrm{G}^{\ddagger}=18.9 \mathrm{kcal} \cdot \mathrm{mol}^{-1}\right.$; Figure 9$)$. The methyl oxidation barrier is only $1.2 \mathrm{kcal} \cdot \mathrm{mol}^{-1}$ lower than the $\mathrm{O}-\mathrm{O}$ bond formation one. These results suggest that the oxidation of the ligand may compete with the O-O bond formation event, providing a rational explanation for the origin of the reduced WO activity of $3 \beta-$ a. 
A)
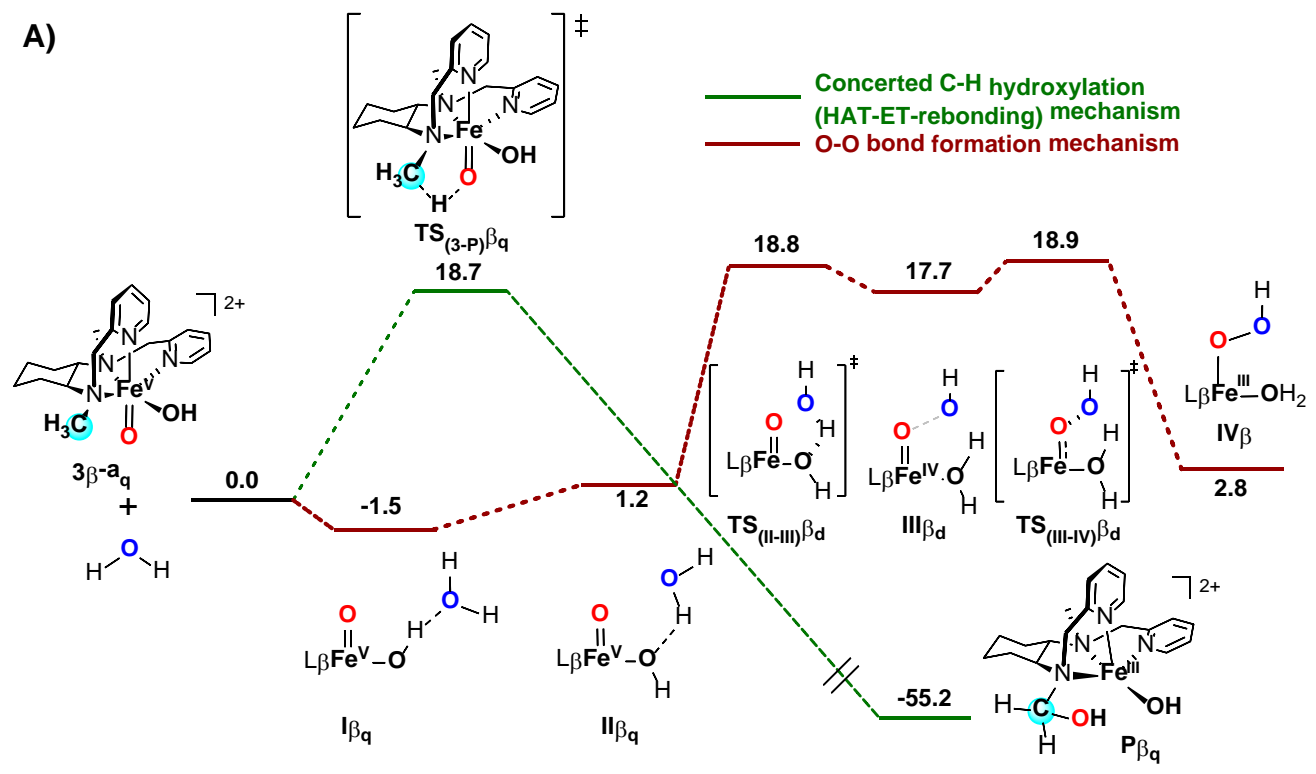

B)
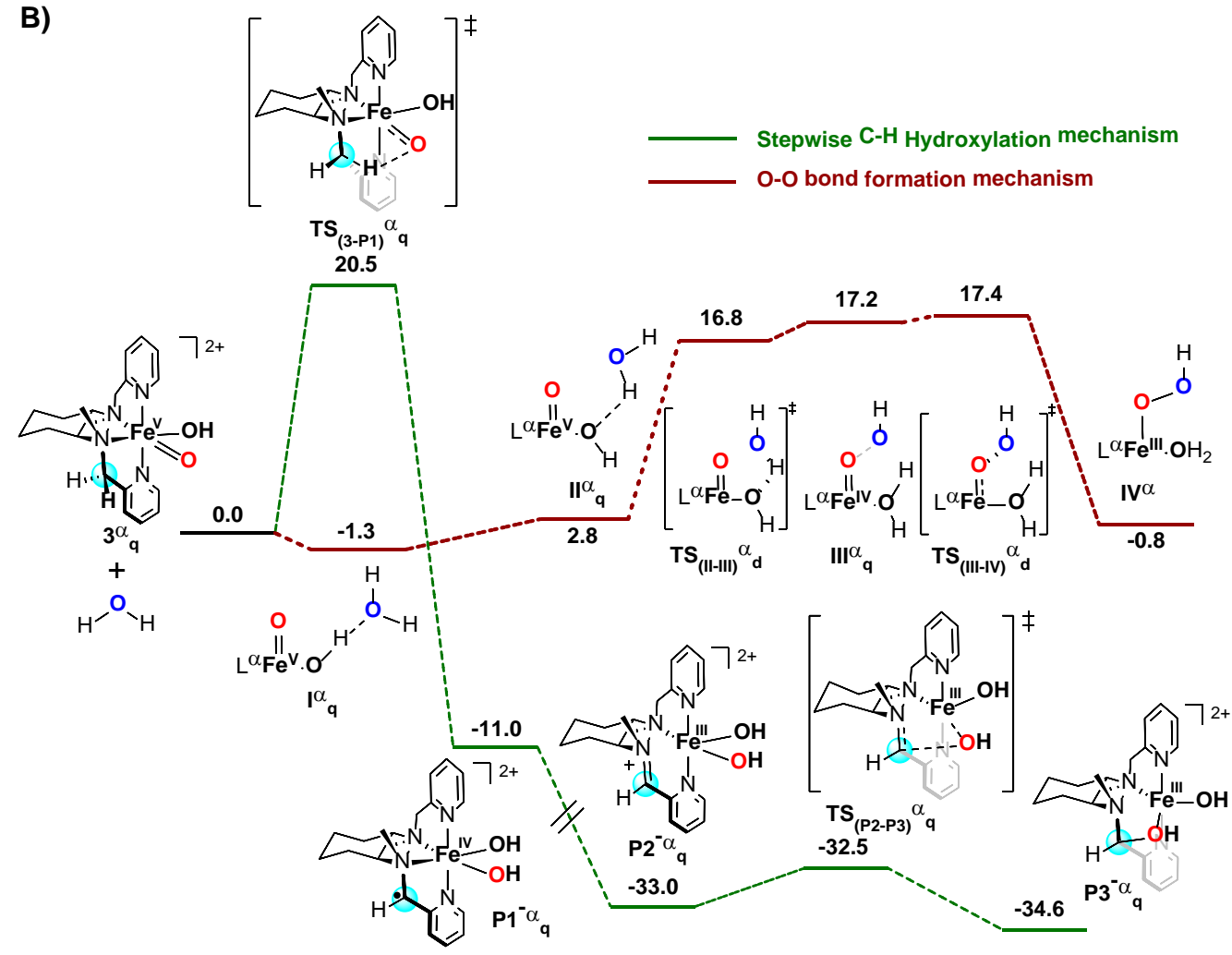

Figure 9. A) Comparison between the $\mathrm{O}-\mathrm{O}$ bond formation and methyl oxidation mechanisms for $3 \beta \mathrm{a}$. B) Comparison between the $\mathrm{O}-\mathrm{O}$ bond formation and methylene oxidation mechanisms for $3 \boldsymbol{\alpha}$. Gibbs energies are in $\mathrm{kcal} \cdot \mathrm{mol}^{-1}$. L stands for the mcp ligand.

For comparison reasons, the same calculations were performed also for $3 \alpha$ (Figure 9B). In this case, the methylene position is easier to oxidize $\left(\Delta \mathrm{G}^{\ddagger}=20.5 \mathrm{kcal} \cdot \mathrm{mol}^{-1}\right)$ than 
the methyl group $\left(\Delta \mathrm{G}^{\ddagger}=25.6 \mathrm{kcal} \cdot \mathrm{mol}^{-1}\right.$, see Figure SI.49). This result is consistent with the methylene oxidation product detected by kinetic and ESI-MS experiments. Most remarkably, in contrast with $3 \beta a$, the transition state for the oxidation of the methylene is $3.5 \mathrm{kcal} \cdot \mathrm{mol}^{-1}$ higher than the barrier for the $\mathrm{O}-\mathrm{O}$ bond formation event.

Therefore, the computational analyses indicate that electrophilic attack of the $\mathrm{Fe}^{\mathrm{v}}(\mathrm{O})$ species over the water molecule, leading to water oxidation is favored over ligand degradation via hydrogen atom transfer from the benzylic C-H bond in $3 \alpha$. Instead, HAT from the N-Me group effectively competes with $\mathrm{O}-\mathrm{O}$ bond formation in $3 \beta$-a. This analysis has obvious consequences that are in line with the experimental observations; a) in first place, $1 \alpha$ is a more robust WOC than $1 \beta$. b) Second, deuteration of the benzylic positions in $1 \alpha$ protects its more sensitive site for ligand oxidation. Owing to the stronger nature of the $\mathrm{C}-\mathrm{D}$ over the $\mathrm{C}-\mathrm{H}$ bond, ligand degradation becomes energetically more demanding. $\mathrm{c}$ ) the most favorable site for ligand degradation in $\mathbf{1} \beta$ is the NMe groups, and consistently, their deuteration limits the oxidative degradation, and enhances its catalytic activity. Deuteration of the pseudobenzylic methylenes in this case does not have a positive effect because these positions are not the most favorable oxidizable sites.

\section{CONCLUSIONS}

In this work the deactivation paths for iron water oxidation catalysts $1 \alpha$ and $1 \beta$ have been studied. High valent oxoiron(IV) complexes $2 \alpha$ and $2 \beta$ have been spectroscopically characterized, providing for the first time Mössbauer evidence for the implication of a high valent iron species in water oxidation reactions with homogeneous catalysts. $2 \alpha$ and $2 \beta$ have been shown to degrade via processes that entail $\mathrm{C}-\mathrm{H}$ oxidation of specific positions of the ligand. Interestingly, the locus of $\mathrm{C}-\mathrm{H}$ oxidation is dependent on the nature of the catalyst, strongly suggesting that this is an intramolecular process, governed by the particular structure of the catalyst. Identification of the deactivation sites has been employed in the design of more robust catalysts by means of the deuteration of the ligand sensitive sites.

Of particular interest deuteration of the benzylic methylenic positions at $1 \alpha$ leads to the preparation of $\mathbf{D}_{\mathbf{4}} \mathbf{- 1} \boldsymbol{\alpha}$, which is an extraordinarily robust and active catalysts. 
Deuteration does not affect the water oxidation reaction rate nor the electronic nature of the catalyst, but the deuterated complex is oxidatively more robust, maintaining catalytic activity longer, and translating into larger TON (up to $1896 \mathrm{TON} \mathrm{O}_{2}$ ). In addition, the lack of induction time in the $\mathrm{O}_{2}$ evolution studies, and the much higher rate for $\mathrm{O}_{2}$ evolution than for $\mathrm{CO}_{2}$ production at the beginning of the reaction strongly suggest that the catalytically active species is molecular. Under specific conditions, using the most robust $\mathbf{D}_{\mathbf{4}} \mathbf{- 1} \boldsymbol{\alpha}$ complex, catalytic activity stops not because of catalyst degradation, but instead because of Nerts effects in the red-ox potential of the $\mathrm{Ce}^{\mathrm{IV}} / \mathrm{Ce}^{\mathrm{III}}$ couple, setting a lower potential of $1.62 \mathrm{~V}$ for the generation of the water oxidation species with this catalyst. Of interest, this value is in agreement with the one determined for the proton transfer electron transfer oxidation of $\left[\mathrm{Fe}^{\mathrm{IV}}(\mathrm{mep})(\mathrm{O})\left(\mathrm{OH}_{2}\right)\right]^{2+}$ to $\left[\mathrm{Fe}^{\mathrm{V}}(\mathrm{mep})(\mathrm{O})(\mathrm{OH})\right]^{2+} .{ }^{8} \mathrm{TON}>3400$ are obtained with $\mathbf{D}_{4}-\mathbf{1 F e}$, which represent the largest numbers obtained for a first row transition metal complex.

Identification of structural weaknesses at molecular scale and its rational prevention provide proof beyond reasonable doubt of the molecular nature of this catalyst, converting the system in a privileged platform for studying $\mathrm{O}-\mathrm{O}$ bond lysis/formation reactions of relevance to biology.

\section{ASSOCIATED CONTENT}

\section{Supporting information}


Sample preparation details and spectroscopic and spectrometric characterization;

spectral simulations of Mössbauer analyses, computational details and coordinates.

\section{AUTHOR INFORMATION}

\section{Corresponding authors}

*jlloret@iciq.es

*miquel.costas@udg.edu

\section{Notes}

The authors declare no competing financial interests.

\section{ACKNOWLEDGMENTS}

We acknowledge the Spanish Ministry of Science CTQ2015-70795-P (M. C.), CTQ201680038-R (J. LL. F.), CTQ2014-59212-P (J. M. Lluis). We would like to thank the European Commission for the ERC-CG-2014-648304 (J.L1.-F) project. The Spanish Ministry of Science is acknowledged for a FPU fellowship to C.C.. The financial support from ICIQ Foundation and CELLEX Foundation through the CELLEX-ICIQ Starting Career Program is gratefully acknowledged. This work has been partially supported by Labex ARCANE and CBH-EUR-GS (ANR-17-EURE-0003)

\section{REFERENCES:}

(1) (a) Blakemore, J. D.; Crabtree, R. H.; Brudvig, G. W. Molecular Catalysts for Water Oxidation. Chem. Rev. 2015, 115, 12974; (b) Karkas, M. D.; Verho, O.; Johnston, E. V.; Akermark, B. Artificial Photosynthesis: Molecular Systems for Catalytic Water Oxidation. Chem. Rev. 2014, 114, 11863; (c) Meyer, T. J.; Sheridan, M. V.; Sherman, B. D. Mechanisms of molecular water oxidation in solution and on oxide surfaces. Chem. Soc. Rev. 2017, 46, 6148.

(2) (a) Blakemore, J. D.; Crabtree, R. H.; Brudvig, G. W. Molecular Catalysts for Water Oxidation. Chem. Rev. 2015, 115, 12974; (b) Stracke, J. J.; Finke, R. G. Distinguishing Homogeneous from Heterogeneous Water Oxidation Catalysis when Beginning with Polyoxometalates. ACS Catal. 2014, 4, 909; (c) Fukuzumi, S.; Jung, J.; Yamada, Y.; Kojima, T.; Nam, W. Homogeneous and Heterogeneous Photocatalytic Water Oxidation by Persulfate. Chem. Asian J. 2016, 11, 1138; (d) Crabtree, R. H. Deactivation in Homogeneous Transition Metal Catalysis: Causes, Avoidance, and Cure. Chem. Rev. 2015, 115, 127. 
(3) Zuccaccia, C.; Bellachioma, G.; Bortolini, O.; Bucci, A.; Savini, A.; Macchioni, A. Transformation of a Cp*-Iridium(III) Precatalyst for Water Oxidation when Exposed to Oxidative Stress. Chem. Eur. J. 2014, 20, 3446.

(4) (a) Fukuzumi, S.; Hong, D. C. Homogeneous versus Heterogeneous Catalysts in Water Oxidation. Eur. J. Inorg. Chem. 2014, 645; (b) Li, J.; Güttinger, R.; Moré, R.; Song, F.; Wan, W.; Patzke, G. R. Frontiers of water oxidation: the quest for true catalysts. Chem. Soc. Rev. 2017, 46, 6124; (c) Wu, X.; Li, F.; Zhang, B.; Sun, L. Molecular complexes in water oxidation: Pre-catalysts or real catalysts. J. Photochem. Photobiol., B: Rev. 2015, 25, 71; (d) Macchioni, A. The Middle-Earth between Homogeneous and Heterogeneous Catalysis in Water Oxidation with Iridium. Eur. J. Inorg. Chem. 2018. 10.1002/ejic.201800798.

(5) (a) Parent, A. R.; Sakai, K. Progress in Base-Metal Water Oxidation Catalysis. Chemsuschem 2014, 7, 2070; (b) Hunter, B. M.; Gray, H. B.; Muller, A. M. EarthAbundant Heterogeneous Water Oxidation Catalysts. Chem. Rev. 2016, 116, 14120; (c) Singh, A.; Spiccia, L. Water oxidation catalysts based on abundant 1st row transition metals. Coord. Chem. Rev. 2013, 257, 2607; (d) Najafpour, M. M.; Renger, G.; Holynska, M.; Moghaddam, A. N.; Aro, E. M.; Carpentier, R.; Nishihara, H.; Eaton-Rye, J. J.; Shen, J. R.; Allakhverdiev, S. I. Manganese Compounds as Water-Oxidizing Catalysts: From the Natural Water-Oxidizing Complex to Nanosized Manganese Oxide Structures. Chem. Rev. 2016, 116, 2886; (e) Karkas, M. D.; Akermark, B. Water oxidation using earth-abundant transition metal catalysts: opportunities and challenges. Dalton Trans 2016, 45, 14421.

(6) (a) Codola, Z.; Gomez, L.; Kleespies, S. T.; Que, L., Jr.; Costas, M.; Lloret-Fillol, J. Evidence for an oxygen evolving iron-oxo-cerium intermediate in iron-catalysed water oxidation (vol 6, 5865, 2015). Nat. Comm. 2015, 6; (b) Codolà, Z.; Garcia-Bosch, I.; Acuña-Parés, F.; Prat, I.; Luis, J. M.; Costas, M.; Lloret-Fillol, J. Electronic Effects on Single-Site Iron Catalysts for Water Oxidation. Chem. Eur. J. 2013, 19, 8042; (c) Fillol, J. L.; Codolà, Z.; Garcia-Bosch, I.; Gómez, L.; Pla, J. J.; Costas, M. Efficient water oxidation catalysts based on readily available iron coordination complexes. Nat. Chem. 2011, 3, 807; (d) Tan, P.; Peng, H.-K.; Lau, T.-C. Catalytic oxidation of water and alcohols by a robust iron(III) complex bearing a cross-bridged cyclam ligand. ChemComm 2014, 50, 12779; (e) Chen, G.; Chen, L.; Ng, S. M.; Man, W. L.; Lau, T. C. Chemical and visiblelight-driven water oxidation by iron complexes at $\mathrm{pH}$ 7-9: Evidence for Dual-active intermediates in iron-catalyzed water oxidation. Angew. Chem. Int. Ed. 2013, 52, 1789; (f) To, W.-P.; Wai-Shan Chow, T.; Tse, C.-W.; Guan, X.; Huang, J.-S.; Che, C.-M. Water oxidation catalysed by iron complex of $\mathrm{N}, \mathrm{N}$ '-dimethyl-2,11-diaza[3,3](2,6)pyridinophane. Spectroscopy of iron-oxo intermediates and density functional theory calculations. Chem. Sci. 2015, 6, 5891; (g) Hong, D.; Mandal, S.; Yamada, Y.; Lee, Y. M.; Nam, W.; Llobet, A.; Fukuzumi, S. Water Oxidation Catalysis with Nonheme Iron Complexes under Acidic and Basic Conditions: Homogeneous or Heterogeneous? Inorg. Chem. 2013, 52, 9522; (h) Das, B.; Lee, B.-L.; Karlsson, E. A.; Akermark, T.; Shatskiy, A.; Demeshko, S.; Liao, R.-Z.; Laine, T. M.; Haukka, M.; Zeglio, E.; Abdel-Magied, A. F.; Siegbahn, P. E. M.; Meyer, F.; Karkas, M. D.; Johnston, E. V.; Nordlander, E.; Akermark, B. Water oxidation catalyzed by molecular di- and nonanuclear Fe complexes: importance of a proper ligand framework. Dalton Trans 2016, 45, 13289; (i) Wickramasinghe, L. D.; Zhou, R.; Zong, R.; Vo, P.; Gagnon, K. J.; Thummel, R. P. Iron Complexes of Square Planar Tetradentate Polypyridyl-Type Ligands as Catalysts for Water Oxidation. J. Am. Chem. Soc. 2015, 137, 13260; (j) Coggins, M. K.; Zhang, M.-T.; Vannucci, A. K.; Dares, C. J.; Meyer, J. Electrocatalytic Water Oxidation by a Monomeric Amidate-Ligated Fe ( III ) Aqua Complex. J. Am Chem. Soc. 2014, 136, 5531-5534; (k) Liu, Y.; Xiang, R.; Du, X.; Ding, Y.; Ma, B. An efficient oxygen evolving catalyst based on a $\mu-O$ diiron coordination complex. Chem. Commun. 2014, 50, 12779; (I) Klepser, B. M.; Bartlett, B. M. Anchoring a Molecular Iron Catalyst to Solar-Responsive WO3 Improves the Rate and Selectivity 
of Photoelectrochemical Water Oxidation. J. Am. Chem. Soc. 2014, 136, 1694; (m) Panchbhai, G.; Singh, W. M.; Das, B.; Jane, R. T.; Thapper, A. Mononuclear Iron Complexes with Tetraazadentate Ligands as Water Oxidation Catalysts. Eur. J. Inorg. Chem. 2016, 2016, 3262; (n) Najafpour, M. M.; Safdari, R.; Ebrahimi, F.; Rafighi, P.; Bagheri, R. Water oxidation by a soluble iron(iii)-cyclen complex: new findings. Dalton Trans 2016, 45, 2618; (o) Annunziata, A.; Esposito, R.; Gatto, G.; Cucciolito, M. E.; Tuzi, A.; Macchioni, A.; Ruffo, F. Iron(III) Complexes with Cross-Bridged Cyclams: Synthesis and Use in Alcohol and Water Oxidation Catalysis. Eur. J. Inorg. Chem. 2018, 2018, 3304; (p) Das, B.; Orthaber, A.; Ott, S.; Thapper, A. Iron Pentapyridyl Complexes as Molecular Water Oxidation Catalysts: Strong Influence of a Chloride Ligand and $\mathrm{pH}$ in Altering the Mechanism. ChemSusChem 2016, 9, 1178; (q) Coggins, M. K.; Zhang, M.T.; Vannucci, A. K.; Dares, C. J.; Meyer, T. J. Electrocatalytic Water Oxidation by a Monomeric Amidate-Ligated Fe(III)-Aqua Complex. J. Am. Chem. Soc. 2014, 136, 5531; (r) Kottrup, K. G.; Hetterscheid, D. G. H. Evaluation of iron-based electrocatalysts for water oxidation - an on-line mass spectrometry approach. Chem. Commun. 2016, 52, 2643; (s) Wang, Z.-Q.; Wang, Z.-C.; Zhan, S.; Ye, J.-S. A water-soluble iron electrocatalyst for water oxidation with high TOF. Appl. Catal., A 2015, 490, 128; (t) Kottrup, K. G.; D'Agostini, S.; van Langevelde, P. H.; Siegler, M. A.; Hetterscheid, D. G. $\mathrm{H}$. Catalytic Activity of an Iron-Based Water Oxidation Catalyst: Substrate Effects of Graphitic Electrodes. ACS Catal. 2018, 8, 1052.

(7) Esarey, S. L.; Holland, J. C.; Bartlett, B. M. Determining the Fate of a Non-Heme Iron Oxidation Catalyst Under Illumination, Oxygen, and Acid. Inorg. Chem. 2016, 55, 11040. (8) Acuna-Pares, F.; Codola, Z.; Costas, M.; Luis, J. M.; Lloret-Fillol, J. Unraveling the mechanism of water oxidation catalyzed by nonheme iron complexes. Chem. Eur. J. 2014, 20, 5696.

(9) (a) Yoshida, M.; Masaoka, S.; Abe, J.; Sakai, K. Catalysis of Mononuclear Aquaruthenium Complexes in Oxygen Evolution from Water: A New Radical Coupling Path using Hydroxocerium(IV) Species. Chem. Asian J. 2010, 5, 2369; (b) Kimoto, A.; Yamauchi, K.; Yoshida, M.; Masaoka, S.; Sakai, K. Kinetics and DFT studies on wateroxidation by $\mathrm{Ce} 4+$ catalyzed by $[\mathrm{Ru}(\mathrm{terpy})(\mathrm{bpy})(\mathrm{OH} 2)] 2+$. Chem. Commun. 2012, 48, 239; (c) Stull, J. A.; Britt, R. D.; McHale, J. L.; Knorr, F. J.; Lymar, S. V.; Hurst, J. K. Anomalous Reactivity of Ceric Nitrate in Ruthenium "Blue Dimer"-Catalyzed Water Oxidation. J. Am. Chem. Soc. 2012, 134, 19973; (d) Bucci, A.; Menendez Rodriguez, G.; Bellachioma, G.; Zuccaccia, C.; Poater, A.; Cavallo, L.; Macchioni, A. An Alternative Reaction Pathway for Iridium-Catalyzed Water Oxidation Driven by Cerium Ammonium Nitrate (CAN). ACS Catal. 2016, 6, 4559.

(10) Acuña-Parés, F.; Costas, M.; Luis, J. M.; Lloret-Fillol, J. Theoretical study of the water oxidation mechanism with non-heme Fe(Pytacn) iron complexes. Evidence that the FelV $(\mathrm{O})($ Pytacn) species cannot react with the water molecule to form the O-O bond. Inorg. Chem. 2014, 53, 5474.

(11) Sala, X.; Maji, S.; Bofill, R.; García-Antón, J.; Escriche, L.; Llobet, A. Molecular Water Oxidation Mechanisms Followed by Transition Metals : State of the Art. Acc. Chem. Res. 2014, 47.

(12) (a) Okamura, M.; Kondo, M.; Kuga, R.; Kurashige, Y.; Yanai, T.; Hayami, S.; Praneeth, V. K.; Yoshida, M.; Yoneda, K.; Kawata, S.; Masaoka, S. A pentanuclear iron catalyst designed for water oxidation. Nature 2016, 530, 465; (b) Staehle, R.; Tong, L. P.; Wang, L.; Duan, L. L.; Fischer, A.; Ahlquist, M. S. G.; Sun, L. C.; Rau, S. Water Oxidation Catalyzed by Mononuclear Ruthenium Complexes with a 2,2 '-Bipyridine-6,6 '-dicarboxylate (bda) Ligand: How Ligand Environment Influences the Catalytic Behavior. Inorg. Chem. 2014, 53, 1307; (c) Parent, A. R.; Nakazono, T.; Lin, S.; Utsunomiya, S.; Sakai, K. Mechanism of water oxidation by non-heme iron catalysts when driven with sodium periodate. Dalton Trans 2014, 43, 12501; (d) Liao, R.-Z.; Li, X.-C.; Siegbahn, P. E. M. Reaction Mechanism of Water Oxidation Catalyzed by Iron Tetraamido Macrocyclic 
Ligand Complexes - A DFT Study. Eur. J. Inorg. Chem. 2014, 728; (e) Ertem, M. Z.; Gagliardi, L.; Cramer, C. J. Quantum chemical characterization of the mechanism of an iron-based water oxidation catalyst. Chem. Sci. 2012, 3, 1293; (f) Ellis, W. C.; McDaniel, N. D.; Bernhard, S.; Collins, T. J. Fast Water Oxidation Using Iron. J. Am. Chem. Soc. 2010, 132, 10990.

(13) (a) Takashima, T.; Ishikawa, K.; Irie, H. Detection of Intermediate Species in Oxygen Evolution on Hematite Electrodes Using Spectroelectrochemical Measurements. J. Phys. Chem. C, 2016, 120, 24827; (b) Zandi, O.; Hamann, T. W. Determination of photoelectrochemical water oxidation intermediates on haematite electrode surfaces using operando infrared spectroscopy. Nat Chem 2016, 8, 778.

(14) Chen, J. Y. C.; Dang, L.; Liang, H.; Bi, W.; Gerken, J. B.; Jin, S.; Alp, E. E.; Stahl, S. S. Operando Analysis of NiFe and Fe Oxyhydroxide Electrocatalysts for Water Oxidation: Detection of Fe4+ by Mössbauer Spectroscopy. J. Am. Chem. Soc. 2015, 137, 15090.

(15) McDonald, A. R.; Que, L., Jr. High-valent nonheme iron-oxo complexes: Synthesis, structure, and spectroscopy. Coord. Chem. Rev. 2013, 257, 414.

(16) Garcia-Bosch, I.; Company, A.; Frisch, J. R.; Torrent-Sucarrat, M.; Cardellach, M.; Gamba, I.; Guell, M.; Casella, L.; Que, L.; Ribas, X.; Luis, J. M.; Costas, M. O-2 Activation and Selective Phenolate ortho Hydroxylation by an Unsymmetric Dicopper mueta(1):eta(1)-Peroxido Complex. Angew Chem. Int. Ed. 2010, 49, 2406.

(17) (a) Wang, D.; Ray, K.; Collins, M. J.; Farquhar, E. R.; Frisch, J. R.; Gomez, L.; Jackson, T. A.; Kerscher, M.; Waleska, A.; Comba, P.; Costas, M.; Que, L., Jr. Nonheme oxoiron(IV) complexes of pentadentate N5 ligands: spectroscopy, electrochemistry, and oxidative reactivity. Chem. Sci. 2013, 4, 282; (b) Garcia-Bosch, I.; Codolà, Z.; Prat, I.; Ribas, X.; Lloret-Fillol, J.; Costas, M. Iron-catalyzed C-H hydroxylation and olefin cisdihydroxylation using a single-electron oxidant and water as the oxygen-atom source. Chem. Eur. J. 2012, 18, 13269; (c) Park, J.; Lee, Y.-M.; Nam, W.; Fukuzumi, S. Bronsted Acid-Promoted C-H Bond Cleavage via Electron Transfer from Toluene Derivatives to a Protonated Nonheme Iron(IV)-Oxo Complex with No Kinetic Isotope Effect. J. Am. Chem. Soc. 2013, 135, 5052.

(18) Detz, R. J.; Abiri, Z.; Kluwer, A. M.; Reek, J. N. H. A Fluorescence-Based Screening Protocol for the Identification of Water Oxidation Catalysts. ChemSusChem 2015, 8, 3057.

(19) the IRC analysis shows a smooth ligand hydroxylation, attempts to obtain additional intermediates in the energy surface always end up in formation of the same product. 
TOC

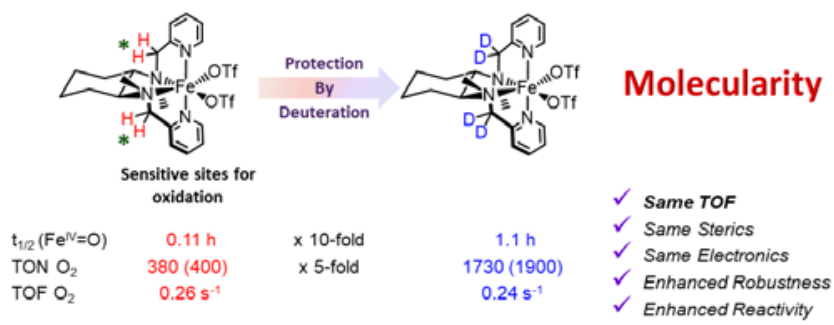

